\title{
Biodiesel production using solid metal oxide catalysts
}

\author{
A. A. Refaat \\ Department of Chemical Engineering, Faculty of Engineering, Cairo University, Egypt
}

Received 4 June 2010; $\quad$ revised 18 October 2010; accepted 18 November 2010; available online 1 December 2010

\begin{abstract}
Biodiesel production is worthy of continued study and optimization of production procedures due to its environmentally beneficial attributes and its renewable nature. Heterogeneous transesterification is considered to be a green process. The process requires neither catalyst recovery nor aqueous treatment steps and very high yields of methyl esters can be obtained, close to the theoretical value. However, heterogeneously catalyzed transesterification generally requires more severe operating conditions, and the performance of heterogeneous catalysts is generally lower than that of the commonly used homogeneous catalysts. Heterogeneous catalysis for biodiesel production has been extensively investigated in the last few years. Many metal oxides have been studied for the transesterification process of oils; these include alkali earth metal oxides, transition metal oxides, mixed metal oxides and supported metal oxides. The use of solid metal oxides as catalysts in oil transesterification is well established, accordingly, researchers' attempts are now focused on how to attain the highest catalyst activity. Catalyst activity is a function of its specific surface area, base strength and base site concentration. High specific surface area, strong base strength and high concentration of base sites are characteristics of an active transesterification catalyst. This review provides a brief overview of the different metal oxides frequently used in the process of transesterification of oils for the production of biodiesel with special reference to the various methods of catalyst preparation and catalyst characterization. Reaction conditions and catalyst leaching analysis are also highlighted. Finally, concluding remarks regarding catalyst selection and catalyst preparation steps are provided.
\end{abstract}

Key words: Catalyst characterization; Catalyst preparation; Catalyst selection; Heterogeneous catalysis; Leaching; Transesterification

\section{INTRODUCTION}

Biodiesel is a renewable, biodegradable, environmentally benign, energy efficient, substitution fuel which can fulfill energy security needs without sacrificing engine's operational performance (van Gerpen, 2005). Thus it provides a feasible solution to the twin crises of fossil fuel depletion and environmental degradation. Transesterification is the general term used to describe the important class of organic reactions where an ester is transformed into another through interchange of the alkoxy moiety (Freedman et al., 1986). Basecatalyzed transesterification is the most commonly used technique as it is the most economical process (Singh et al, 2006). Base-catalyzed transesterification involves stripping the glycerin from the fatty acids with a catalyst such as sodium or potassium hydroxide, and replacing it with an anhydrous alcohol, usually methanol. The

凶*Corresponding Author Email: aarefaat@hotmail.com Tel./Fax: +2012227 7897 resulting raw product is then centrifuged and washed with water to cleanse it of impurities. This yields methyl or ethyl ester (biodiesel), as well as a smaller amount of glycerol, a valuable by-product used in making soaps, cosmetics, and numerous other products (Knothe et al., 2005). An alternative method for the production of biodiesel is to use heterogeneous (solid) catalysts in the transesterification process. Heterogeneous (solid) catalysts have the general advantage of easy separation from the reaction medium and reusability. Heterogeneous catalysis is thus considered to be a green process. The process requires neither catalyst recovery nor aqueous treatment steps: the purification steps of products are then much more simplified and very high yields of methyl esters, close to the theoretical value, are obtained (Cao et al., 2008). Glycerin is directly produced with high purity levels (at least $98 \%$ ) and is exempt from any salt contaminants (Melero et al., 2008; Bournay et al., 2005). 
However, heterogeneously catalyzed transesterification generally requires more severe operating conditions (relatively elevated temperatures and pressures), and the performance of heterogeneous catalysts is generally lower than that of the commonly used homogeneous catalysts (Refaat, 2010). Moreover, one of the main problems with heterogeneous catalysts is their deactivation with time owing to many possible phenomena, such as poisoning, coking, sintering, and leaching (Sivasamy et al., 2009). The problem of poisoning is particularly evident when the process involves used oils (Lam et al., 2010). More general and dramatic is catalyst leaching, which not only can increase the operational cost as a result of replacing the catalyst but also leads to product contamination. In general, the best catalysts must have several qualities i.e., catalyze transesterification and esterification, not be deactivated by water, be stable, do not give rise to leaching, be active at low temperature, and have high selectivity (Di Serio et al., 2008). Thus far, the use of solid catalysts to produce biodiesel requires a better understanding of the factors that govern their reactivity. To improve the performance of these catalysts, it is essential to understand the correlations between acid and base strength and catalytic activity. It is clear that the surface of these heterogeneous materials should display some hydrophobic character to promote the preferential adsorption of triglycerides and to avoid deactivation of catalytic sites by strong adsorption of polar by-products such as glycerol and water (Lotero et al., 2005).Heterogeneous catalysis for biodiesel production has been extensively investigated in the last few years. Many metal oxides have been studied for the transesterification process of oils; these include alkali earth metal oxides, transition metal oxides, mixed metal oxides and supported metal oxides. This review provides a brief overview of the different metal oxides frequently used in the process of transesterification of oils for the production of biodiesel with special reference to the various methods of catalyst preparation and catalyst characterization. Reaction conditions and catalyst leaching analysis will be also highlighted.

\section{Catalyst selection}

Heterogeneously catalyzed methanolysis reaction is very complex because it occurs in a three-phase system consisting of a solid (heterogeneous catalyst) and two immiscible liquid phases (oil and methanol). Also, concurrently with methanolysis, there are some side reactions such as saponification of glycerides and methyl esters and neutralization of free fatty acids by catalyst (Veljkovic et al., 2009). Fig. 1 shows a simplified flowsheet of a heterogeneous transesterification process.

The catalyst efficiency depends on several factors such as specific surface area, pore size, pore volume and

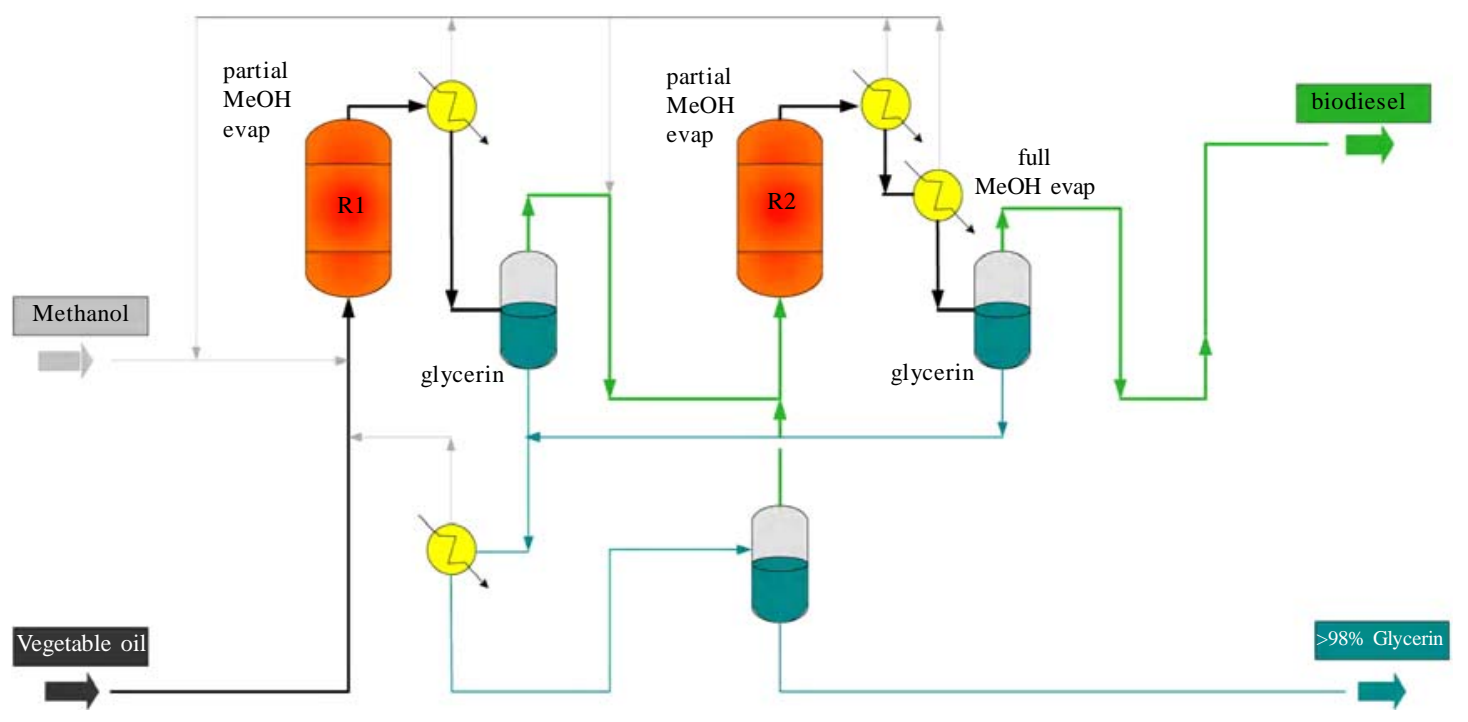

Fig. 1: Flowsheet of Heterogeneous Transesterification Process (Bournay et al., 2005). 


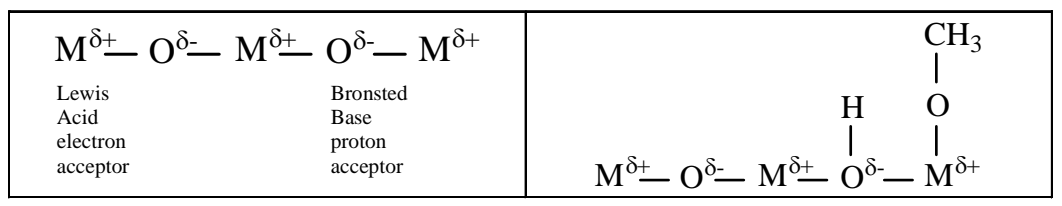

Fig. 2: Surface structure of metal oxides (Chorkendorff and Niemantsverdriet, 2003)

active site concentration (Smith and Notheisz, 2006). The structure of metal oxides is made up of positive metal ions (cations) which possess Lewis acidity, i.e. they behave as electron acceptors, and negative oxygen ions (anions) which behave as proton acceptors and are thus Brønsted bases. This has consequences for adsorption. In methanolysis of oils, it provides sufficient adsorptive sites for methanol, in which the $(\mathrm{O}-\mathrm{H})$ bonds readily break into methoxide anions and hydrogen cations (Fig. 2). The methoxide anions then react with triglyceride molecules to yield methyl esters (Chorkendorff and Niemantsverdriet, 2003). Liu et al. (2008a) found that small amounts of water can improve the catalytic activity of $\mathrm{CaO}$ and biodiesel yields because in the presence of water, $\mathrm{O}^{-2}$ on the surface of the catalyst extracts $\mathrm{H}^{+}$from water molecules to form $\mathrm{OH}^{-}$which subsequently extracts $\mathrm{H}^{+}$of methanol to form methoxide anions, which are the real catalyst of the transesterification reaction. However, if too much water (more than $2.8 \%$ by weight of oil) is added to methanol, the fatty acid methyl ester will hydrolyze under basic conditions to generate fatty acids, which can react with $\mathrm{CaO}$ to form soap. Dossin et al. (2006a, 2006b) showed that the transesterification reaction occurs between the methanol molecules adsorbed on a magnesium oxide free basic sites. The methanol adsorption is assumed to be the rate-determining step in catalysts such as $\mathrm{MgO}$ and $\mathrm{La}_{2} \mathrm{O}_{3}$ while the surface reaction step becomes rate-determining with catalysts having a higher basicity, such as $\mathrm{BaO}, \mathrm{CaO}$ or $\mathrm{SrO}$. Calcium oxide is the metal oxide catalyst most frequently applied for biodiesel synthesis, probably due to its cheap price, minor toxicity and high availability (Lee et al., 2009). It can be synthesized from cheap sources like limestone and calcium hydroxide. Calcium oxide possesses relatively high basic strength and less environmental impacts due to its low solubility in methanol (Zabeti et al., 2009) and its easier handling as compared to KOH(Sakai et al., 2009). A study by Kawashima et al. (2008) has investigated thirteen different kinds of metal oxides containing calcium, barium, magnesium, or lanthanum for transesterification. The results suggested that the Ca series catalysts have higher catalytic activity for the transesterification reaction. Transesterification of edible soybean oil with refluxing methanol was carried out in the presence of calcium oxide $(\mathrm{CaO})$, -hydroxide $\left(\mathrm{Ca}(\mathrm{OH})_{2}\right)$, or -carbonate $\left(\mathrm{CaCO}_{3}\right)$. At 1 $\mathrm{h}$ of reaction time, yield of FAME was $93 \%$ for $\mathrm{CaO}, 12 \%$ for $\mathrm{Ca}(\mathrm{OH})_{2}$, and $0 \%$ for $\mathrm{CaCO}_{3}$. Kouzu et al. (2008) reported that under the same reacting condition, sodium hydroxide with the homogeneous catalysis brought about the complete conversion into FAME. The authors added that $\mathrm{CaO}$ will probably bring about as the good productivity as $\mathrm{NaOH}$ do, by taking advantage of the easy product recovery and the environmentally benign process. Sakai et al. (2009) confirmed this advantage by conducting an economic feasibility study on four batch processes for the production of biodiesel using a homogeneous $\mathrm{KOH}$ catalyst and a heterogeneous $\mathrm{CaO}$ catalyst with hot water purification process and vacuum FAME distillation process. Among the four processes, the manufacturing costs involved in the $\mathrm{CaO}$ catalyst with hot water purification process proved to be the lowest.

Liu et al. (2008b) investigated calcium methoxide to catalyze transesterification of soybean oil to biodiesel with methanol and found that calcium methoxide has strong basicity and high catalytic activity as a heterogeneous solid base catalyst and a $98 \%$ biodiesel yield was obtained within $2 \mathrm{~h}$ in this reaction. The order of reactivity $\mathrm{Ca}(\mathrm{OH})_{2}<\mathrm{CaO}<\mathrm{Ca}\left(\mathrm{CH}_{3} \mathrm{O}\right)_{2}$ agrees with the Lewis basic theory: the methoxides of alkaline-earth metals are more basic than their oxides which are more basic than their hydroxides. In a further study, Kouzu et al., (2010) argued that since alcohols are very reactive with calcium oxide, even at room temperature, it is possible that calcium methoxide functioned as the solid base catalyst under the reacting condition and not calcium oxide. Huang et al., (2009) demonstrated the efficiency of magnesium methoxide as a catalyst in the transesterification process and showed that the use of heterogeneous catalysts was mass transfer limited.

Other alkali earth oxides, like for instance SrO, present high activity but they are fully dissolved in the reaction medium that means that in such cases the catalysis is 
considered homogeneous (Granados et al., 2007; Gryglewicz, 1999). Magnesium oxide which is produced by direct heating of magnesium carbonate or magnesium hydroxide has the weakest basic strength and solubility in methanol among group II oxides (Zabeti et al., 2009). Gryglewicz (1999, 2000) investigated the possibility of using alkaline-earth metal hydroxides, oxides, and alkoxides to catalyze the transesterifiction of rapeseed oil at methanol reflux temperature. The author found that sodium hydroxide was the most active, barium hydroxide was slightly less active, and that calcium methoxide showed medium activity. The reaction rate was lowest when $\mathrm{CaO}$ powder was used as catalyst while magnesium oxide and calcium hydroxide showed no catalytic activity. The high activity of barium hydroxide was attributed to its higher solubility in methanol with respect to other compounds.

Abreu et al. (2005) showed that tin oxide was active for soybean oil methanolysis in a heterogeneous system achieving reaction yields of up to $93 \%$ in $3 \mathrm{~h}$ at $60^{\circ} \mathrm{C}$. The authors also reported that they were able to recover and reuse the catalyst three times without any loss of catalytic activity. Zirconium oxide, titanium oxide and zinc oxide are among the transition metal oxides that have attracted attention for biodiesel production due to their acidic properties (Zabeti et al., 2009). There have been several reports on the usage of zirconia as a solid acid catalyst for transesterification of different oils rather than other transition metal oxides due to its strong acidity and it was found that the acidity is promoted when the surface of these metal oxides contains anions like sulfate and tungstate. Sulfated zirconia showed more activity toward conversion of triacetin than tungstated zirconia owing to its higher specific surface area and active phase concentration under the same conditions (López et al., 2005).

Sulfated zirconia $\left(\mathrm{SO}_{4}^{-2} / \mathrm{ZrO}_{2}\right)$, sulfated tin oxide $\left(\mathrm{SO}_{4}^{-}\right.$ $\left.{ }^{2} / \mathrm{SnO}_{2}\right)$ and sulfated titanium oxide $\left(\mathrm{SO}_{4}^{-2} / \mathrm{TiO}_{2}\right)$ have been studied to catalyze the transesterification of vegetable oils owing to their superacidity. These catalysts have shown good catalytic activities and good stability when used to catalyze esterification and transesterification simultaneously. However, they have not been generally used in the industrial production process, mainly because of the high catalyst cost and difficulty in filtering the small catalyst particles. Furuta et al. (2004) compared the activity of sulfated tin oxide and zirconium oxide and tungstated zirconia under the same reaction conditions and found that WZO showed the highest activity for conversion of soybean oil whereas $70 \%$ and $80 \%$ conversions were reached over SZO and STO respectively. Jitputti et al. (2006) investigated $\mathrm{ZrO}_{2}$, ZnO, $\mathrm{SO}_{4}^{-2} / \mathrm{SnO}_{2}, \mathrm{SO}_{4}^{-2} / \mathrm{ZrO}_{2}, \mathrm{KNO}_{3} / \mathrm{KL}$ zeolite and $\mathrm{KNO}_{3} / \mathrm{ZrO}$ as heterogeneous catalysts for the transesterification of crude palm kernel oil and crude coconut oil. Their study found that the order of activity of the solid catalysts for crude palm kernel oil transesterification is $\mathrm{SO}_{4}^{-2} / \mathrm{ZrO}_{2}>$ $\mathrm{SO}_{4}^{-2} / \mathrm{SnO}_{2}>\mathrm{ZnO}>\mathrm{KNO}_{3} / \mathrm{ZrO}_{2}>\mathrm{KNO}_{3} / \mathrm{KL}$ zeolite $>\mathrm{ZrO}_{2}$. In the case of crude coconut oil, the activity can be shown from highest to lowest as follows: $\mathrm{SO}_{4}^{-2} / \mathrm{ZrO}_{2}>\mathrm{SO}_{4}^{-2} /$ $\mathrm{SnO}_{2}>\mathrm{ZnO}>\mathrm{KNO}_{3} / \mathrm{KL}$ zeolite $>\mathrm{KNO}_{3} / \mathrm{ZrO}_{2}>\mathrm{ZrO}_{2}$. The $\mathrm{SO}_{4}^{-2} / \mathrm{ZrO}_{2}$ system can yield up to $90.3 \mathrm{wt}$. $\%$ of methyl esters from crude palm kernel oil and $86.3 \mathrm{wt}$ \% from crude coconut oil. Kiss et al. (2006) studied various solid catalysts and also founded that sulfated zirconia is the most promising catalyst.

The activities of three modified-zirconias (titania zirconia, sulfated zirconia, and tungstated zirconia) were evaluated for both esterification and transesterification reactions (Lopez et al., 2008). The study provided a quantitative comparison of the rate of transesterification and conversion of TGs versus the rate of esterification of FFAs under simultaneous reaction conditions, which is of great importance when using less pure biodiesel feedstock (such as waste cooking oil). As expected, esterification occurred at a much faster rate than transesterification. However, under simultaneous reaction conditions, by virtue of the water being produced in esterification and hydrolysis of the TG taking place, the conversion of the triglycerides to ester products was greatly increased. Although the fresh sulfated zirconia (SZ) catalyst was found to be the most active for these reactions, its activity was not easily regenerated. Titania zirconia (TiZ) was found to have a greater activity for transesterification than tungstated zirconia (WZ). However, the opposite result was found for esterification. The higher activity of TiZ towards transesterification is suggested to be due to its base sites, which are likely poisoned in the presence of the carboxylic acid during esterification. WZ was found to be the most suitable of these catalysts for carrying out these reactions as it is more active than TiZ for esterification and can be more easily regenerated than SZ by simple re-calcination in air.

In a pioneering work by Peterson and Scarrah (1984) the activities of different metal oxides to catalyze transesterification of rapeseed oil to biodiesel have been studied. They have reported that the most promising catalyst examined was $\mathrm{CaO}-\mathrm{MgO}$. The activities of the catalysts $\mathrm{CaO}$ and $\mathrm{ZnO}$ appeared to be enhanced with the addition of $\mathrm{MgO}$, therefore they argued that the 
transesterification reaction mechanism may be, in this instance, bifunctional, but $\mathrm{MgO}$ caused soap formation in the reaction process. Tanabe and Hoelderich (1999) reviewed industrial application of solid acid and base catalysts. They counted the number of solid acid, base, and acid-base bifunctional catalysts used in industrial processes as 127 . Among them are included 10 solid base catalysts and 14 solid acid-base bifunctional catalysts. $\mathrm{MgO}-\mathrm{La}_{2} \mathrm{O}_{3}$ and $\mathrm{CaO}-\mathrm{La}_{2} \mathrm{O}_{3}$ complexes were also investigated as transesterification catalysts (Yan et al., 2009a, 2009b; Babu et al., 2008), they both showed high activity on biodiesel production, but $\mathrm{CaO}-\mathrm{La}_{2} \mathrm{O}_{3}$ deactivated rapidly when exposed to air. Yang and Xie (2007) compared the catalyst performance of alkali earth metals loaded on different catalyst supports for soybean oil conversion to biodiesel and discovered a correlation between loading amount of catalyst precursor on support and the conversion of oil. They also found that the catalyst performance is depending upon concentration of basic sites on the surface of the catalyst.Supporting of the alkali metal compound on a large surface area is an interesting option for decreasing the amount of catalyst required to still obtain a similar level of catalytic activity. Accordingly, the transesterification of triolein using alkali loaded on alumina achieved a high conversion yield, making it of interest to apply in biodiesel production (Ebiura et al., 2005). Samart et al. (2010) showed that mesoporous silica as a Ca loading support improved the transesterification efficiency of this alkali-supported catalyst. The most suitable condition was a reaction temperature of 60p C for $8 \mathrm{~h}$, with a $15 \mathrm{wt} . \%$ Ca loaded mesoporous silica catalyst at 5 wt.\% by oil weight. Ngamcharussrivichai et al. (2008) have investigated Ca and Zn mixed oxide catalysts for transesterification. The results indicated that the mixed oxides possess relatively small particle sizes and high surface areas, compared to pure $\mathrm{CaO}$ and $\mathrm{ZnO}$. Moreover, the combination of Ca and $\mathrm{Zn}$ reduced the calcination temperature required for decomposition of metal carbonate precipitates to active oxides. This result emphasizes the advantage of coexistence of two different basic-oxide components in the catalyst for transesterification.

From the aforementioned studies, calcium oxide can be widely applied for biodiesel synthesis owing to its cheap price, minor toxicity and high availability. Calcium oxide possesses relatively high basic strength and less environmental impacts due to its low solubility in methanol. As compared to $\mathrm{KOH} / \mathrm{NaOH}$, calcium oxide will probably bring about similar productivity with added advantages of easy product recovery, easier handling and the environmentally benign process. The usage of zirconia as a solid acid catalyst for transesterification of different oils rather than other transition metal oxides is due to its strong acidity and it was found that the acidity is promoted when the surface of these metal oxides contains anions like sulfate and tungstate. Co-existence of two different basic-oxide components in the catalyst for transesterification has to be also taken into consideration. The selection of an appropriate solid catalyst which could simultaneously carry out esterification of FFAs and transesterification of triglycerides would be of great interest for biodiesel production especially in the case of feedstock which feature high water and free fatty acids (FFAs) content, which strongly affects the behavior of conventional homogeneous base catalysts. Such a problem is usually encountered on using low quality triglyceride-containing raw materials, for instance waste cooking oil or yellow and brown grease, or on using non-edible oils, for instance Jatropha, as feedstock.

\section{Catalyst characterization}

The use of solid metal oxides as catalysts in oil transesterification is well established, accordingly, researchers' attempts are now focused on how to attain the highest catalyst activity. Catalyst activity is a function of its specific surface area, base strength and base site concentration. High specific surface area, strong base strength and high concentration of base sites are characteristics of an active transesterification catalyst. The surface density of base sites, which is a combination of surface area and overall number of base sites, represents a relevant parameter to explain the catalytic behavior in transesterification reactions when different metal oxide solids show similar numbers of strong and very strong base sites (Alonso et al., 2010).

\section{Determination of Surface Area of the Catalyst}

The principle underlying surface area measurements is simple: physisorb an inert gas such as argon or nitrogen and determine how many molecules are needed to form a complete monolayer. As, for example, the $\mathrm{N}_{2}$ molecule occupies $0.162 \mathrm{~nm}^{2}$ at $77.2 \mathrm{~K}$, the total surface area follows directly (Chorkendorff and Niemantsverdriet, 2003). The specific surface area of the catalysts is usually determined by an ASAP 2010 surface area analyzer based on nitrogen adsorption/desorption isotherms acquired at $77.2 \mathrm{~K}$ using a 30 s equilibrium interval. The surface area 
is then computed using the BET (Brunauer-EmmettTeller) model. It is recommended that all catalyst samples should be degassed at $200{ }^{\circ} \mathrm{C}$ for $5 \mathrm{~h}$ prior to analysis to remove any adsorbed molecules from the pores and surfaces.

Yan et al. (2009b) showed that there was a strong interaction between $\mathrm{Ca}$ and La species in the binary catalyst prepared by the ammonia-ethanol-carbon dioxide precipitation method, which resulted in high basicity, high BET surface area and high catalytic activity in oil transesterification. The catalysts prepared by traditional methods have low BET surface areas $\left(<10 \mathrm{~m}^{2} / \mathrm{g}\right)$ as compared to Ca3La1 (62.6 m²/g) (Yan et al., 2010). Increases in $\mathrm{CaO}$ performances can be obtained using nanocrystalline calcium oxides. Reddy et al. (2006) showed that nanocrystalline $\mathrm{CaO}$ was an efficient catalyst in the transesterification of soybean oil owing to the high surface area associated with the presence of small crystallites and lattice defects. The nanocrystalline calcium oxides (crystal size $=20 \mathrm{~nm}$; specific surface area $=90 \mathrm{~m}^{2} / \mathrm{g}$ ) gave $100 \%$ conversion of soybean oil at room temperature after $12 \mathrm{~h}$ while the conversion obtained with commercial $\mathrm{CaO}\left(\right.$ crystal size $=43 \mathrm{~nm}$; specific surface area $=1 \mathrm{~m}^{2} / \mathrm{g}$ ) was only $2 \%$ (Reddy et al., 2006). The specific surface area is an important microstructural parameter of $\mathrm{ZnO}$ particles, which depends on the geometrical shape and porosity of the particles (Music et al., 2007). A specific surface area of $27.22 \mathrm{~m}^{2} / \mathrm{g}$ was measured for $\mathrm{ZnO}$ nanocrystals. Verziu et al. (2008) demonstrated that nanostructured MgO can be used effectively as a heterogeneous catalyst system for biodiesel transesterification and that the facet of $\mathrm{MgO}$ exposed has an important influence regarding activity and selectivity. Leclercq et al. (2006) tested the use of commercial $\mathrm{MgO} / \mathrm{Al}_{2} \mathrm{O}_{3}$ hydrotalcites and $\mathrm{MgO}\left(300 \mathrm{~m}^{2} / \mathrm{g}\right)$ in the transesterification of rapeseed oil. They found that $\mathrm{MgO}$ was more active than hydrotalcite.

Catalytic activity of $\mathrm{ZrO}_{2} / \mathrm{SO}_{4}{ }^{2 "}$ and $\mathrm{ZrO}_{2} / \mathrm{WO}_{3}{ }^{2 "}$ as superacid catalysts in the methanolysis of triacetin was compared by López et al. (2005) and the results indicated that the specific surface area and active site concentration play an important role in the catalyst activity. Sulfated zirconia showed more activity toward conversion of triacetin than tungstated zirconia owing to its higher specific surface area $\left(134 \mathrm{~m}^{2} / \mathrm{g}\right.$ for sulfated zirconia compared to $89 \mathrm{~m}^{2} / \mathrm{g}$ for tungstated zirconia) and active site concentration (94 $\mu \mathrm{mol} / \mathrm{g}$ for sulfated zirconia compared to $54 \mathrm{imol} / \mathrm{g}$ for tungstated zirconia) under the same conditions of $60^{\circ} \mathrm{C}$ and $8 \mathrm{~h}$ of reaction time. Comparing the activity of $\mathrm{TiO}_{2} / \mathrm{SO}_{4}^{2 "}$ and $\mathrm{ZrO}_{2} / \mathrm{SO}_{4}^{2 "}$ as solid strong acid catalysts in the transesterification of cotton seed oil to methyl esters, both catalysts showed high activity. However, higher methyl ester yields were obtained for sulfated titanium oxide due to its higher specific surface area of $99.5 \mathrm{~m}^{2} / \mathrm{g}$ compared to $91.5 \mathrm{~m}^{2} / \mathrm{g}$ for sulfated zirconia (Chen et al., 2007). It was found that after the introduction of sulfate anions new Bronsted acid sites were formed on the catalyst surface. de Almeida et al. (2008) prepared superacid sulfated titania catalyst via the sol-gel technique, with different sulfate concentrations. The catalyst that exhibits the highest catalytic activity in the methanolysis of soybean and castor oils was that which displayed the highest specific surface area $\left(266 \mathrm{~m}^{2} / \mathrm{g}\right)$, average pores diameter $(5.2 \mathrm{~nm})$ and pore volume $\left(0.327 \mathrm{~cm}^{3} / \mathrm{g}\right)$, andhighest percentage in sulfate groups.

From the above studies it is apparent that increases in metal oxide performances can be obtained by using nanocrystalline forms rather than commercial grade catalysts.

\section{Determination of Basicity of the Catalyst}

It has been reported that the base sites over heterogeneous catalysts are active centers for transesterification. Thus, it is interesting to correlate the effects of base strength and basicity of the catalysts on activity. Basicity, that is, the number of exposed basic sites per unit mass will decrease as the specific surface area decreases (Arzamendi et al., 2008). The Hammett indicator method is used to determine the basic strength of the catalyst. According to Hammett scale, when Hammett function $\mathrm{H}$ _of a solid base is over 26, this solid base can be defined as the super solid base or solid superbase (Li et al., 2007). Catalytic performance was shown to be closely related to the density of basic sites (Antunes et al., 2008). Mootabadi et al. (2010) investigated the ultrasonic-assisted transesterification of palm oil in the presence of alkaline earth metal oxide catalysts $(\mathrm{CaO}$, $\mathrm{SrO}$ and $\mathrm{BaO}$ ): The activities of the catalysts were mainly related to their basic strength. The catalytic activity was in the sequence of $\mathrm{CaO}<\mathrm{SrO}<\mathrm{BaO}$. However, it was shown that $\mathrm{CaO}$ has basic sites stronger than $\mathrm{H}_{-}=26.5$ (Liu et al., 2008a) and SrO has basic sites stronger than $\mathrm{H}_{-}=26.5$ (Liu et al., 2007).

Di Serio et al (2006) showed the possibility to use calcined hydrotalcites and MgO for industrial biodiesel production at moderately high temperature. High yields of methyl esters were obtained in $1 \mathrm{~h}$ of reaction time at $180-200^{\circ} \mathrm{C}$. The achieved experimental data showed a correlation not only with the catalysts basicity, but 
also with its structural texture. However, the structural texture of the examined catalysts was dependent on both the precursor and the preparation method (Di Serio et al., 2006). The strongest basic sites (super-basic) promote the transesterification reaction also at very low temperature $\left(100^{\circ} \mathrm{C}\right)$, while the basic sites of medium strength require higher temperatures to promote the same reaction.

Bancquart et al. (2001) compared the base-catalyzed activities of single metal oxides, $\mathrm{La}_{2} \mathrm{O}_{3}, \mathrm{MgO}, \mathrm{CaO}$, and $\mathrm{ZnO}$ and the results confirmed that stronger basicity of the catalysts resulted in their higher activity for transesterification. The authors concluded that the reaction rates by single metal oxides directly depend on the basicity of the oxide, especially of the strong basic sites. Sato et al. (2009) investigated the use of rare earth oxides as transesterification catalysts and reported that rare earth oxides (REOs) have similar basicity as $\mathrm{CaO}$ and that the strength of the basic sites of heavy REOs is dependent upon the radius of the rare earth cation. The basic properties of REOs are related to lanthanide contraction: the number and strength of basic sites of REOs increased with increasing radius of the rare earth cation. $\mathrm{Sc}_{2} \mathrm{O}_{3}$, having the smallest ionic radius, showed the weakest strength of basic sites and the lowest surface density of basic sites. Russbueldt and Hoelderich (2010) investigated a series of rare earth aluminates, titanates, and zirconates as heterogeneous catalysts for the transesterification of different oils and fats with methanol and found that the activity is decreasing in the order La to Sm and Y in parallel to the decreasing ion radius and basicity, leading to an excellent activity for $\mathrm{La}_{2} \mathrm{O}_{3}$. In an optimization study of $\mathrm{La}_{2} \mathrm{O}_{3}$ catalysts in the transesterification of rapeseed oil, the best results of 97.5 \% FAME and 93.8 \% glycerol yield were obtained with $50 \%$ methanol at $200{ }^{\circ} \mathrm{C}$.

Li et al. (2007) prepared a novel solid superbase catalyst of $\mathrm{Eu}_{2} \mathrm{O}_{3} / \mathrm{Al}_{2} \mathrm{O}_{3}$ with basic strength 26.5 measured by indicators according to Hammett scale and BET surface area $103.6 \mathrm{~m}^{2} / \mathrm{g}$. The catalytic activity of $\mathrm{Eu}_{2} \mathrm{O}_{3} / \mathrm{Al}_{2} \mathrm{O}_{3}$ was evaluated for the transesterification of soybean oil with methanol to biodiesel in the fixed bed reactor under atmospheric pressure; and showed high activity. Sun et al. (2010) discussed the relationship between transesterification activity and surface basicity of $\mathrm{La}_{2} \mathrm{O}_{3} / \mathrm{ZrO}_{2}$ catalyst and reported that the catalytic activities showed a correlation with their basic properties towards biodiesel production, which is that, the stronger basicity, the higher biodiesel yield was achieved. The $\mathrm{La}_{2} \mathrm{O}_{3}$ loaded on $\mathrm{ZrO}_{2}$ was an active catalyst for the production of biodiesel from sunflower oil. After calcined at $600 \mathrm{p} \mathrm{C}$ for $4 \mathrm{~h}$, the catalyst with $21 \mathrm{wt} \% \mathrm{La}_{2} \mathrm{O}_{3}$ loaded on $\mathrm{ZrO}_{2}$ was found to be with highest basicity and catalytic activity for the transesterification reaction. Xie and Huang (2006) used ZnO loaded with KF as a solid base catalyst in the transesterification of soybean oil with methanol which showed good activity. In this case, the activity of the catalysts correlated well with their basicity. The best performances were observed with a $\mathrm{KF}$ loading of $15 \mathrm{wt} \%$. The catalytic activity of $\mathrm{ZrO}_{2}$ in the transesterification reaction increased as it was enriched with more potassium anions as the catalyst became more basic (Georgogianni et al., 2009a, 2009b). Also, when different metal loading were used in the biodiesel production over heterogeneous catalysts, it was possible to observe how the incorporation of sodium increased the basic strength and the number of basic sites of the parent zeolite, increasing also the catalytic activity for producing methyl esters (Ramos et al., 2008).

\section{Catalyst preparation}

Several methods for the preparation of solid catalysts for the transesterification process were described in the literature. These methods include: thermal pretreatment, hydrothermal synthesis, physical mixing, impregnation, and precipitation.

\section{Calcination (Thermal Treatment)}

The surfaces of metal oxides are covered with carbon dioxide, water, and in some cases, oxygen as they are handled in air. To have basic sites exposed on the surfaces, pre-treatment at high temperatures is required. The nature of the surface basic sites varies with severity of pre-treatment conditions. Beside removal of water and carbon dioxide, rearrangement of surface and bulk atoms occurs during pre-treatment, which changes the number and nature of the basic sites with increasing the pre-treatment temperature. Therefore, the optimum pre-treatment temperature varies with the type of reaction (Hattori, 2001). As the pre-treatment temperature increases, the molecules covering the surfaces are successively desorbed according to the strength of the interaction with the surface sites. The molecules weakly interact with the surfaces are desorbed at lower pre-treatment temperatures, and those strongly interacting are desorbed at higher temperatures. The sites that appear on the surfaces by pre-treatment at low temperatures are suggested to be different from those appearing at high temperatures. If 
simple desorption of molecules occurs during pretreatment, the basic sites that appear at high temperatures should be strong. However, rearrangement of surface and bulk atoms also occurs during pre-treatment, which may change the number and nature of the surface basic sites with increasing the pre-treatment temperature (Hattori, 2004).

The active surface sites of $\mathrm{CaO}$ are unavoidably poisoned by the atmospheric $\mathrm{H}_{2} \mathrm{O}$ and $\mathrm{CO}_{2}$. The catalytic activity of $\mathrm{CaO}$ can be improved if before the reaction the $\mathrm{CaO}$ is subjected to an activation treatment to remove and to clean the surface of the main poisoning species (the carbonate groups) and if after this treatment the contact with room air is prevented (Granados et al., 2007). used the activated calcium oxide as a solid base catalyst in the methanolysis of sunflower oil to investigate the role of water and carbon dioxide on the deterioration of the catalytic performance by contact with air for different periods of time. The study showed that $\mathrm{CaO}$ is rapidly hydrated and carbonated in air. As a result, in order to avoid reduction of $\mathrm{CaO}$ catalytic activity, the catalyst was thermally treated at $700^{\circ} \mathrm{C}$ in order to chemically desorb $\mathrm{CO}_{2}$ before being used in the reaction. Calcium oxide as a heterogeneous catalyst was investigated for its effect on the biodiesel synthesis from refined sunflower oil by Vujicic et al. (2010). In order to investigate the influence of temperature of the catalyst activation on biodiesel yield the authors prepared two batches of catalysts differing only in the calcination temperature: 500 and $900{ }^{\circ} \mathrm{C}$. It was shown that the catalyst activation in static air conditions at $900{ }^{\circ} \mathrm{C}$ preceding the reaction is necessary for the sake of strong basic sites formation. Zhu et al._(2006) prepared a solid super base by dipping $\mathrm{CaO}$ in ammonium carbonate solution. The results showed that the base strength of calcium oxide was more than 26.5 after dipping in an ammonium carbonate solution followed by calcination. After calcination at $850{ }^{\circ} \mathrm{C}$, the catalyst showed high activity for the transesterification process. When the calcination temperature was over $900^{\circ} \mathrm{C}$, the catalytic activity gradually decreased.

Arzamendi et al., 2008 claimed that basic catalysts have to be activated, usually by means of hightemperature thermal treatments and outgassing, in order to remove water and surface carbonates thus developing catalytic activity. The authors added that in the case of $\mathrm{CaO}$ and $\mathrm{MgO}$, basic sites appear upon treatments above $673 \mathrm{~K}$; however, very strong basic sites such as those required to form the methoxide anion do not appear for samples calcined in air. For example, Dossin et al. (2006) subjected a commercial MgO powder to a pretreatment under dry nitrogen at $973 \mathrm{~K}$ for $12 \mathrm{~h}$ in order to remove any adsorbed $\mathrm{CO}_{2}$ and water and prevent any contact with the ambient air; the solid was active in the transesterification of ethyl acetate with methanol (Dossin et al., 2006b). The generation of very active coordinatively unsaturated $\mathrm{O}^{2-}$ acting as Lewis basic sites requires very high pretreatment temperatures (Xie et al., 2006). Leclercq et al. (2006) showed that the transesterification of rapeseed oil with methanol could be efficiently performed over a high-surface-area (300 $\mathrm{m}^{2} \mathrm{~g}$ ) magnesium oxide to give a high conversion of the vegetable oil and a high yield of methyl esters, particularly when the hydroxide precursor was calcined at $550^{\circ} \mathrm{C}$.

The activity of zirconium oxide functionalized with tungsten oxide was studied by López et al. (2007) to investigate the effect of calcination temperatures on the catalytic properties of $\mathrm{ZrO}_{2} / \mathrm{WO}_{3}{ }^{2 "}$ as a solid strong acid for transesterification of triacetin. The most active catalyst was obtained after calcination of $800^{\circ} \mathrm{C}$ with the formation of Bronsted acid sites concentration of 161 ìmol/g. The catalyst was active for both transesterification and esterification reactions although the reaction time was relatively long. On the other hand, Ramu et al. (2004) evaluated the effect of calcinations temperature on the catalytic performance of $\mathrm{ZrO}_{2} / \mathrm{WO}_{3}{ }^{2 "}$ as well as the effect of amount of $\mathrm{WO}_{3}$ loading on the zirconium oxide for the esterification of palmitic acid with methanol and discovered that the catalyst which was calcined at $500^{\circ} \mathrm{C}$ had the most activity. This activity was attributed to the formation of tetragonal phase of $\mathrm{ZrO}_{2}$. Beyond $500^{\circ} \mathrm{C}$ the tetragonal phase transferred to the monoclinic phase which caused a decrease in the activity from $98 \%$ conversion of palmitic acid to $8 \%$ for the catalyst which was calcined at $900^{\circ} \mathrm{C}$. With $5 \mathrm{wt} . \%$ loading of $\mathrm{WO}_{3}$ the acid site concentration of $1.04 \mathrm{mmol} / \mathrm{g}$ was achieved. The acidity which is correlated to the activity decreased by increasing the amount of $\mathrm{WO}_{3}$ as a result of excess coverage of $\mathrm{WO}_{3}$ species on $\mathrm{ZrO}_{2}$. Xie and Yang (2007) investigated the transesterification of soybean oil using a Ba-ZnO catalyst. The results showed that with an increase in the calcination temperature from 400 to 600p $\mathrm{C}$, the basicity of the catalysts increased which resulted in an improvement in the conversion. However, at calcination temperatures higher than 600p C, there was a decrease both in the basicity of the $\mathrm{Ba}-\mathrm{ZnO}$ catalysts as well as in the conversion of the soybean oil. 


\section{Hydrothermal Method}

$\mathrm{ZnO}$ nanorods were synthesized in supercritical water with a simple hydrothermal method using flowthrough experimental apparatus from $\mathrm{KOH}$ and $\mathrm{Zn}\left(\mathrm{NO}_{3}\right)_{2}$ aqueous solutions at $673 \mathrm{~K}$ and $30 \mathrm{MPa}$. The order of preheating and mixing of the solutions was very important and leads to difference crystal morphologies. Preheating the $\mathrm{Zn}\left(\mathrm{NO}_{3}\right)_{2}$ solutions leads to $\mathrm{ZnO}$ nanorods. Synthesized nanorods has an average length/width of 230/38 nm (Sue et al., 2004). Continuous supercritical hydrothermal synthesis has advantages for preparing highly crystallized nanoparticles with narrow size distribution and high purity without further calcination step. Particle size, morphology, and crystal structure can be controlled by varying synthesis conditions such as temperature, pressure, and time (Sue et al., 2004).

Veriansyah et al. (2010) examined the continuous hydrothermal synthesis of decanoic acid-modified and oleic acid-modified $\mathrm{ZnO}$ nanoparticles in scMeOH. The usage of scMeOH and the surface modifiers changed drastically the shape and size of the nanoparticles. Nanorods shape particles with a clear facet were obtained when $\mathrm{scH}_{2} \mathrm{O}$ was used whereas spherically shape particles with $130-360 \mathrm{~nm}$ in diameter were obtained when scMeOH was used. When the surface modifiers were used, primary particles with diameter of 7-13nm loosely aggregated and formed secondary particles with the diameter of 25-100 nm. The FT-IR spectra indicated that the surface of $\mathrm{ZnO}$ was modified with the surface modifiers. The surface area of $\mathrm{ZnO}$ increased from 0.7 to $36 \mathrm{~m}^{2} / \mathrm{g}$ by reducing the particle size when a large amount of the surface modifier was used (molar ratio of surface modifier to $\left.\mathrm{Zn}\left(\mathrm{NO}_{3}\right)_{2}=30: 1\right)$. The continuous synthesis mode and short residence time (typically less than $1 \mathrm{~min}$ ) is amenable to commercial-scale production of the nanoparticles.

Yoosuk et al. (2010) proposed a hydrothermal technique for increasing the transesterification activity of $\mathrm{CaO}$. Hydration and subsequent calcination of $\mathrm{CaO}$ proved to increases both the specific surface area and the amount of basic site. The BET surface area of the commercial grade $\mathrm{CaO}$ was increased from $2.1 \mathrm{~m}^{2} / \mathrm{g}$ to 25 $\mathrm{m}^{2} / \mathrm{g}$ and the crystalline size was decreased from $>100$ $\mathrm{nm}$ to $42.2 \mathrm{~nm}$. Subsequently, transesterification of palm olein was enhanced 18.4 wt.\%. $\mathrm{CaCO}_{3}$ was thermally decomposed at $800 \mathrm{p} \mathrm{C}$ for $3 \mathrm{~h}$. The solid product $(\mathrm{CaO})$ was refluxed in water at $60 \mathrm{p} \mathrm{C}$ for $6 \mathrm{~h}$, and the sample was filtered and heated at 120p C overnight. Prior to use, the product was calcined at $600 \mathrm{p} \mathrm{C}$ for $3 \mathrm{~h}$ in order to change the hydroxide form to an oxide form, the latter being the active form for the transesterification reaction. This technique has also been demonstrated previously in MgO (Aramendia et al., 1999).

\section{Impregnation Methods}

Albuquerque et al. (2008) prepared a series of $\mathrm{CaO}$ catalysts supported on mesoporous silica using an impregnation method, and Wen, L. et al. (2010) prepared $\mathrm{KF} / \mathrm{CaO}$ nanocatalyst by using impregnation method. Park et al. (2008) prepared zinc oxide nanostructures with zinc acetate and activated carbon by impregnation using a matrix-assisted method. ZnO nanostructures have a great advantage to apply to a catalytic reaction process due to their large surface area and high catalytic activity. Zinc oxide, obtained by thermal decomposition of zinc oxalate, has been impregnated with different amounts of calcium oxide, and used as solid catalyst for transesterification processes (albaRubio et al., 2010). Calcium oxide is stabilized by filling the mesoporous network of $\mathrm{ZnO}$, as revealed by the corresponding pore size distributions, thus avoiding the lixiviation of the active phase in the reaction medium. These supported $\mathrm{CaO}$ catalysts, thermally activated at $1073 \mathrm{~K}$, can give rise to FAME (fatty acid methyl esters) yield higher than $90 \%$, after $2 \mathrm{~h}$ of reaction, when a methanol:oil molar ratio of $12: 1$ and 1.3 wt \% of the catalyst with a 16 wt \% $\mathrm{CaO}$ were employed.

Attempts have been made to promote the basicity of the alkali earth oxides by doping with an alkali metal such as lithium (Li). Alkali metal (Li, Na, K)-impregnated calcium oxide catalysts were prepared and used for the transesterification of karanja oil by Meher et al. (2006). The authors reported that $\mathrm{Li} / \mathrm{CaO}$ is a promising heterogeneous catalyst for biodiesel production and that its performance was not significantly affected by the presence of a high FFA content up to $5.75 \%$. The yield of methyl esters only decreased from 94.9 to 90.3 wt- \% when the FFA content of the oil was increased from 0.48 to $5.75 \%$. In a further study, the same authors investigated a series of alkali metal ( $\mathrm{Li}, \mathrm{Na}, \mathrm{K})$ promoted alkali earth oxides ( $\mathrm{CaO}, \mathrm{BaO}, \mathrm{MgO})$, as well as $\mathrm{K}_{2} \mathrm{CO}_{3}$ supported on alumina $\left(\mathrm{Al}_{2} \mathrm{O}_{3}\right)$, as catalysts for the transesterification of canola oil with methanol (D'Cruz et al., 2007). Alkali metal (Li, Na, K) promoted $\mathrm{BaO}$ were effective for transesterification, however, ICP-MS analysis revealed that leaching of barium in ester phase was too high ( $>1,000$ ppm) when $\mathrm{BaO}$ based catalysts were used. As barium is highly toxic, these catalysts 
are not recommended for transesterification processes. Also, potassium-supported $\mathrm{TiO}_{2}$ catalyst was successfully used for the transesterification of canola oil by Salinas et al. (2010).

Xie et al. (2007) have prepared Li/ZnO catalyst using an impregnation method followed by calcinations for the transesterification of soybean oil. It was shown that the activity of the catalysts for the transesterification reaction is closely related to their basic properties. $\mathrm{Li}$ / $\mathrm{ZnO}$ catalysts exhibited good catalytic activities, and the catalytic performance was greatly dependent on the loading amount of lithium and the calcination temperature. Similar conclusions were achieved by Alonso et al. (2009) who studied a series of catalyst with different amounts of lithium supported on $\mathrm{CaO}$. It was found that a lithium amount above $4.5 \mathrm{wt} \%$ is required to promote the catalytic activity of $\mathrm{CaO}$ in the transesterification of sunflower oil. Moreover, the activation process to obtain an active catalyst was determined. The catalyst starts to be active when activation temperature was higher than the melting point of $\mathrm{LiNO}_{3}(492 \mathrm{~K})$. Above $773 \mathrm{~K}$, the influence of the activation temperature is not significant for catalytic activity, but it is for homogeneous contribution. When $\mathrm{Li}_{2} \mathrm{O}$ has been formed, active species are leached in the reaction medium and catalysis is mainly homogeneous; nevertheless, at lower temperatures when $\mathrm{LiNO}_{3}$ is present on $\mathrm{CaO}$, heterogeneous contribution must be responsible for the activity because any possible $\mathrm{LiNO}_{3}$ leached in the reaction medium is not active. The promoter effect of $\mathrm{LiNO}_{3}$ has been observed in a sample activated at $773 \mathrm{~K}$. At activation temperatures between 773 and $973 \mathrm{~K}$, an intermediate situation will be expected.

Yang and Xie (2007) showed that the strontium metaldoped $\mathrm{ZnO}$, which was prepared by an impregnation method followed by calcination at a higher temperature, can be used as a catalyst for the transesterification of soybean oil with methanol. The loading amount of 2.5 mmol Sr$\left(\mathrm{NO}_{3}\right)_{2} / \mathrm{g}$ on $\mathrm{ZnO}$ and calcination at $873 \mathrm{~K}$ for 5 $\mathrm{h}$ was found to be the conditions for preparing the optimum catalyst, which could exhibit the highest basicity and the best catalytic activity. A maximum conversion of $94.7 \%$ was achieved using a 1:12 molar ratio of soybean oil to methanol and a catalyst amount of 5 wt. \% at reflux of methanol for $5 \mathrm{~h}$. The SrO derived from thermal decomposition of $\mathrm{Sr}\left(\mathrm{NO}_{3}\right)_{2}$ at high calcinations temperatures is probably the main catalytically active specie. However, the used catalyst was significantly deactivated and could not be directly reused for transesterification. Yang and Xie explained the deactivation by the deposition of reactants and products on the active sites and/or by a transformation of the active sites and their interactions during the reaction. However, the leaching of $\mathrm{SrO}$ was not examined; notwithstanding, its high solubility in the reaction environment is known.

The preparation of a Li-doped MgO for biodiesel synthesis has been investigated by optimizing the catalyst composition and calcination temperatures. The results show that the formation of strong base sites is particularly promoted by the addition of $\mathrm{Li}$, thus resulting in an increase of the biodiesel synthesis. The catalyst with the $\mathrm{Li} / \mathrm{Mg}$ molar ratio of 0.08 and calcination temperature of $823 \mathrm{~K}$ exhibits the best performance. The biodiesel conversion decreases with further increasing $\mathrm{Li} / \mathrm{Mg}$ molar ratio above 0.08 , which is most likely attributed to the separated lithium hydroxide formed by excess $\mathrm{Li}$ ions and a concomitant decrease of BET values (Wen, Z. et al., 2010). MgO was prepared by hydration with distilled water of the low surface area commercial magnesium oxide. Then, the resulting $\mathrm{Mg}(\mathrm{OH})_{2}$ was decomposed and stabilized at $773 \mathrm{~K}$ in a He flow for $18 \mathrm{~h}$ to obtain the high-surface area $\mathrm{MgO}\left(137 \mathrm{~m}^{2} / \mathrm{g}\right)$. A series of Li-doped $\mathrm{MgO}$ samples were prepared by the incipient wetness impregnation with the $\mathrm{Li} / \mathrm{Mg}$ molar ratio in the range of 0.02-0.15. A similar approach was conducted by Wan et al. (2008) in which biodiesel was synthesized from rapeseed oil by transesterification over magnesium oxide loaded with KF. It was also shown that the catalytic activity strongly depends on the loading amount of KF and calcined temperature. The authors found that the reaction reached a $79.37 \%$ yield when the loading amount was at $35 \mathrm{wt} \%$ and calcined at $500^{\circ} \mathrm{C}$. The simply dried $30 \% \mathrm{KF} / \mathrm{MgO}$ at $80{ }^{\circ} \mathrm{C}$ was found to give equally good results from the catalyst calcined at $500^{\circ} \mathrm{C}$, avoiding the usual activation at high temperature. The catalyst was prepared by using the impregnation method. MgO was doped in the aqueous solution containing the desired amount of $\mathrm{KF}$, air dried for $6 \mathrm{~h}$ at $80^{\circ} \mathrm{C}$, and calcined at different temperatures (typically at $500^{\circ} \mathrm{C}$ ) in air for $3 \mathrm{~h}$. The measured BET surface area and the pore volume decrease to about half of the $\mathrm{MgO}$ when it is loaded with 30 wt \% KF (measured BET surface area decreased from $25.51 \mathrm{~m}^{2} / \mathrm{g}$ to $13.70 \mathrm{~m}^{2} / \mathrm{g}$ ). Another example of surface extension is the silica-supported sulfated titania reported by Peng et al .(2008). This catalyst has been prepared by impregnation of silica with titanium isopropoxide and consequent calcination, followed by impregnation with sulfuric acid and re-calcination. The so-prepared material displayed improved textural properties compared with 
conventional sulfated titania. This material was used in the simultaneous esterification and transesterification of an oleic acid-refined cotton seed oil mixture with methanol.

\section{Physical Mixing Methods}

It has been reported that high-loading of active components cannot be easily obtained using an impregnation method (Wang et al., 2006). High loading of active components can be obtained using physical mixing (Wang et al., 2006). A major drawback of the physical mixing method is low crystallinity of the catalyst which has a negative effect on catalytic activity. Furthermore, a high-loading catalyst generally results in a low specific surface area, and thus low surface concentration of catalytic sites for transesterification. Kawashima et al. (2008) produced different kinds of metal oxide catalysts using a physical mixing method.

\section{Precipitation Methods}

Precipitation methods show promise to obtain a high concentration of active catalytic sites (Sree, 2009). Wang et al. (2006) prepared $\mathrm{CaO}-\mathrm{ZrO}_{2}$ catalysts using ammonia solution as precipitant and Ngamcharussrivichai et al. (2008) prepared $\mathrm{Ca}$ and $\mathrm{Zn}$ mixed oxide catalysts using $\mathrm{Na}_{2} \mathrm{CO}_{3}$ as precipitant. $\mathrm{Al}_{2} \mathrm{O}_{3} / \mathrm{ZrO}_{2} / \mathrm{WO}_{3}$ solid acid catalyst was prepared by co-precipitating method and was investigated in the methanolysis of soybean oil (Furuta et al., 2006). Macedo et al. (2006) prepared catalysts obtained from the co-precipitation of aluminum, tin and zinc oxides using an aqueous solution of sodium carbonate. Recently, Nanometer magnetic solid base catalysts were prepared by loading $\mathrm{CaO}$ on $\mathrm{Fe}_{3} \mathrm{O}_{4}$ with $\mathrm{Na}_{2} \mathrm{CO} 3$ and $\mathrm{NaOH}$ as precipitator, respectively (Liu et al., 2010). $\mathrm{Ca}_{2} \mathrm{Fe}_{2} \mathrm{O}_{5}$, a new kind of crystalloid with high catalytic activity, is formed by calcining the precursors. This achieves assembly of magnet and catalytic activity. The catalytic activity of catalysts which are obtained by calcining $\mathrm{Ca}(\mathrm{OH})_{2}-\mathrm{Fe}_{3} \mathrm{O}_{4}$ has proved to be better than that by calcining $\mathrm{CaCO}_{3}-\mathrm{Fe}_{3} \mathrm{O}_{4}$. Furthermore, the authors reported that $\mathrm{Ca}^{2+}: \mathrm{Fe}_{3} \mathrm{O}_{4}=7$ has shown to be the optimum proportion for catalytic activity. The conversion rate of transesterification reaction catalyzed by $\mathrm{Ca}(\mathrm{OH})_{2} 7$ reached $95 \%$ in $80 \mathrm{~min}$, and $99 \%$ in $4 \mathrm{~h}$.

A recent study by Yan et al (2010) argued that a single precipitant cannot effectively precipitate all metal ions in solution. So, they proposed a multistep precipitation method with ammonia solution, ethanol and carbon dioxide as precipitants for solid base catalyst preparation. Such a precipitation process utilized ammonia solution (as base precipitant), carbon dioxide (as acid precipitant) and ethanol (as neutral precipitant) in a sequential manner. The produced $\mathrm{CaO}-\mathrm{La}_{2} \mathrm{O}_{3}$ based catalyst prepared by this novel method was compared with those prepared by physical mixing, impregnation, and co-precipitation methods. The authors reported that the cooperative effect among the precipitants allowed a more complete and uniform precipitation process, a higher specific BET surface area, higher concentration of strong base sites, and a high catalytic activity in the oil transesterification reaction for biodiesel production. The previous overview has demonstrated the importance of catalyst preparation step. From the several methods described above for the preparation of solid catalysts for the transesterification process: either a single method or a combination of more than one method can be used to attain the highest catalyst activity.

\section{Operation conditions}

Granados et al. (2007) used the activated calcium oxide as a solid base catalyst in the methanolysis of sunflower oil and showed that after $100 \mathrm{~min}$ of reaction time, $94 \%$ conversion was obtained at $60^{\circ} \mathrm{C}$ with alcohol/oil molar ratio of 13:1 and catalyst content of 3 wt. \% based on the weight of oil. Similar results were obtained by Liu et al., (2008a) who used 12:1 alcohol/ oil molar ratio, $65^{\circ} \mathrm{C}$ reaction temperature and $8 \mathrm{wt}$. \% catalysts, but with the addition of 2.03 wt. \% water into the reaction medium. The methyl ester yields exceeded $95 \%$ within $3 \mathrm{~h}$ of reaction time compared to $80 \%$ under anhydrous conditions. Demirbas (2007) described the effect of the supercritical conditions on the catalytic transesterification of sunflower oil in the presence of 3 wt. \% CaO 60-120 mesh, 40:1 alcohol/oil molar ratio, at $252^{\circ} \mathrm{C}$ and pressure of $24 \mathrm{MPa}$. and found that after 26 min of reaction time $98.9 \%$ methyl ester yields were obtained. In contrast to Granados et al. (2007); Liu et al. (2008); Demirbas (2007) argued that the calcium oxide catalytic performance is quite weak at low temperatures since only $5 \%$ methyl ester yields were obtained at $60^{\circ} \mathrm{C}$ after 3 h.Kawashima et al. (2009) studied the catalytic activity of calcium oxide for the transesterification of rapeseed oil with methanol. The authors highlighted the need for an optimal catalyst activation protocol. The authors argued that, by pretreating $\mathrm{CaO}$ with methanol, a small amount of $\mathrm{CaO}$ was converted into $\mathrm{Ca}\left(\mathrm{OCH}_{3}\right)_{2}$, which acted as the initiating reagent for transesterification. Subsequently, the calcium-glycerol complex formed in the reaction of $\mathrm{CaO}$ with glycerol functioned as the main catalyst in transesterification. Under optimal reaction conditions (0.1 
Heterogeneous Transesterification

Table 1 Summary of Catalyst Preparation for Different Metal Oxide Catalysts

\begin{tabular}{|c|c|c|c|c|}
\hline Catalyst & Preparation Method & Technique & Yield (\%) & Reference \\
\hline $\mathrm{CaO}$ & Calcination & $700^{\circ} \mathrm{C}$ & 94 & Granados et al. (2007) \\
\hline $\mathrm{CaO}$ & Calcination & $900^{\circ} \mathrm{C}$ & 91 & Vujicic et al. (2010) \\
\hline $\mathrm{CaO}$ & Calcination & $900^{\circ} \mathrm{C}$ & 93 & Zhu et al. (2006) \\
\hline $\mathrm{CaO}$ & Hydrothermal & Hydration + Calcination $\left(800^{\circ} \mathrm{C}\right)$ & 93.9 & Yoosuk et al. (2010) \\
\hline $\mathrm{CaO} / \mathrm{Li}$ & Impregnation & Wet impregnation $(\mathrm{Li})$ & 94.9 & Meher et al. 2006 \\
\hline $\mathrm{CaO} / \mathrm{KF}$ & Impregnation + Calcination & $(\mathrm{KF})+\left(600^{\circ} \mathrm{C}-4 \mathrm{~h}\right)$ & 96.8 & Wen, et al. (2010) \\
\hline $\mathrm{MgO}$ & Calcination & $700^{\circ} \mathrm{C}$ & 93 & Dossin et al. (2006b) \\
\hline $\mathrm{MgO} / \mathrm{Li}$ & Impregnation + Calcination & $(\mathrm{Li})+\left(600^{\circ} \mathrm{C}\right)$ & 89.1 & Wen, et al. (2010) \\
\hline $\mathrm{ZnO}$ & Hydrothermal & Supercritical hydrothermal synthesis & 100 & Sue et al. (2004) \\
\hline $\mathrm{ZnO} / \mathrm{Li}$ & Impregnation + Calcination & $(\mathrm{Li})+\left(600^{\circ} \mathrm{C}-5 \mathrm{~h}\right)$ & 96.3 & Xie et al. (2007) \\
\hline $\mathrm{ZnO} / \mathrm{Ba}$ & Impregnation + Calcination & (Ba nitrate) $+\left(600^{\circ} \mathrm{C}-5 \mathrm{~h}\right)$ & 95.8 & Xie and Yang (2007) \\
\hline $\mathrm{ZnO} / \mathrm{KF}$ & Impregnation + Calcination & $(\mathrm{KF})+\left(600^{\circ} \mathrm{C}-5 \mathrm{~h}\right)$ & 87 & Xie et al. (2006) \\
\hline $\mathrm{ZrO}_{2} / \mathrm{WO}_{3}{ }^{2} ?$ & Impregnation + Calcination & $\left(\mathrm{WO}_{3}\right)-500^{\circ} \mathrm{C}$ & 98 & Ramu et al. (2004) \\
\hline
\end{tabular}

g CaO, 3.9 g methanol, $15 \mathrm{~g}$ oil, and $1.5 \mathrm{~h}$ activation time at room temperature), the methyl ester was obtained in approximately $90 \%$ yield within $3 \mathrm{~h}$ at $60^{\circ} \mathrm{C}$.

Wang and Yang (2007) showed that Nano-MgO had higher catalytic activity in the supercritical/subcritical temperatures. At the stirring rate of $1000 \mathrm{rpm}$ with $3 \mathrm{wt} \%$ nano-MgO, the transesterification reaction was essentially completed (more than $99 \%$ yield) within 10 min under $533^{\circ} \mathrm{K}$ and high pressure of $28.7 \mathrm{MPa}$ and with the methanol/oil molar rate of 36:1. Such high reaction rate with nano-MgO was mainly attributed to the lower activation energy (75.94 kJ/mol) and the higher stirring. Transesterification of soybean oil with $\mathrm{SrO}$ as a solid base catalyst showed that although the specific surface area of the catalyst is as low as $1.05 \mathrm{~m}^{2} / \mathrm{g}, 90 \%$ yields of methyl esters were achieved after $30 \mathrm{~min}$ of reaction time at $65^{\circ} \mathrm{C}$ with alcohol/oil molar ratio of $12: 1$ and 3 wt.\% catalyst. The catalyst was stable even after 10 reaction cycles (Liu et al., 2007). Mootabadi et al. (2010) investigated the ultrasonic-assisted transesterification of palm oil in the presence of alkaline earth metal oxide catalysts ( $\mathrm{CaO}, \mathrm{SrO}$ and $\mathrm{BaO})$ : Reaction conditions: methanol to oil molar ratio 9:1, ultrasonic power level 50\% and catalyst mass ratio $3 \%$ ). At optimum conditions, 60 min was required to achieve $95 \%$ yield compared to 2-4 $\mathrm{h}$ with conventional stirring.

Jitputti et al. (2006) assessed the catalytic performance of zinc oxide and zirconium oxide as solid acid catalysts in transesterification reaction of palm kernel oil at supercritical methanol and found that after $1 \mathrm{~h}$ of reaction time, using 3 wt. \% catalyst and 6:1 molar ratio of alcohol/ oil, $86.1 \%$ methyl ester yields were obtained for zinc oxide while only $64.5 \%$ for zirconium oxide. However, using sulfated zirconia, the yields considerably increased to 90.3 $\%$ which might be due to high acidic strength of sulfate anions on the surface of zirconia. Chen et al., (2007) found that by introducing 2 wt. \% catalyst and 12:1 alcohol/oil molar ratio, in the transesterification of cotton seed oil to methyl esters, after $8 \mathrm{~h}$ of reaction time the methyl ester yields in the presence of $\mathrm{TiO}_{2} / \mathrm{SO}_{4}{ }^{2 "}$ and $\mathrm{ZrO}_{2} / \mathrm{SO}_{4}{ }^{2 "}$ were $90 \%$ and $85 \%$ respectively. Furuta et al. (2004) studied conversion of soybean oil over tungstated zirconia and found that the catalyst activity remained stable up to 100 $\mathrm{h}$ of use. After reaction time of $8 \mathrm{~h}$ at $300^{\circ} \mathrm{C}, 94 \%$ of oil was converted with alcohol/oil molar ratio of 40:1. $\mathrm{Al}_{2} \mathrm{O}_{3} / \mathrm{ZrO}_{2} /$ $\mathrm{WO}_{3}$ solid acid catalyst was prepared by co-precipitating method and was investigated in the methanolysis of soybean oil (Furuta et al., 2006). The catalyst was compatible for both esterification and transesterification reaction and under reaction conditions of temperature of $250^{\circ} \mathrm{C}$ and alcohol/oil molar ratio of $40: 1$ methyl ester yields of $90 \%$ were obtained. This catalyst was also compared to $\mathrm{Al}_{2} \mathrm{O}_{3} / \mathrm{ZrO}_{2}$; however, the yields were $80 \%$. Park et al. (2010) stated that the optimum reaction conditions for tungsten oxide zirconia transesterification with a FFA conversion of $96 \%$ were 20 wt. $\% \mathrm{WO}_{3} / \mathrm{ZrO}_{2}$ at $150 \mathrm{p} \mathrm{C}, 0.4 \mathrm{~g} / \mathrm{ml}$ (oil), 9:1 (alcohol to oil, molar ratio) and $2 \mathrm{~h}$ reaction time.

Yang and Xie (2007) compared the catalyst performance of alkali earth metals loaded on different catalyst supports for soybean oil conversion to biodiesel and found that after $5 \mathrm{~h}$ of reaction time, at $65^{\circ} \mathrm{C}$, with 12:1 molar ratio of alcohol/oil and 5 wt. \% of catalyst content, the maximum conversion achieved was $93.7 \%$. In order to study the effect of cosolvent on the conversion of soybean oil to biodiesel, Yang and Xie applied different co-solvents such as THF, DMSO and n-hexane and THF was found as the most effective cosolvent since the conversion of soybean oil increased to $96.8 \%$. Peng et al., (2008) studied the activity of a 
solid acid catalyst comprising $\mathrm{SO}_{4}^{2-} / \mathrm{TiO}_{2}-\mathrm{SiO}_{2}$ for the production of biodiesel from several low cost feedstock with high FFAs. The optimized reaction parameters were reaction temperature $200^{\circ} \mathrm{C}$, molar ratio of methanol to oil 9:1 and catalyst concentration 3 wt. \%. They reported that the catalyst showed good stability, can be recycled, easily removed and can simultaneously catalyze esterification and transesterification. A continuous process for biodiesel production from cheap raw feedstock was proposed and a 10,000-tonnes/year biodiesel production demonstration plant has been built. Li-doped $\mathrm{CaO}$ catalyst at a concentration of 2 wt- \%, resulted in $94.9 \mathrm{wt}-\%$ of methyl esters in $8 \mathrm{~h}$ at a reaction temperature of 65p C and a 12:1 molar ratio of methanol to oil, during methanolysis of karanja oil (Meher et al., 2006).

Most of the presented studies have shown that the use of heterogeneous catalysts would result in high biodiesel yields, simpler and cheaper separation processes, a reduced water effluent load, and a higher grade of glycerol could be obtained. On the other hand, the main drawbacks are the high temperature and pressure, as well as the higher methanol to oil ratio needed for the transesterification reaction as compared with homogeneous systems. Some of these catalysts have shown a good catalytic performance even under reaction conditions similar to those used for the homogeneous catalysts. However, this kind of catalyst is still far from an industrial application, since its evaluation has only been carried out in stirred batch reactors, there being few studies on continuous processes using packed bed flow reactors.

\section{Leaching analysis}

Leaching affects the industrial application as extensive leaching may threaten the reusability and the environmental sustainability of catalyst (Granados et al., 2009). Ca concentration in the biodiesel is limited by strict regulations; moreover, the degree of leaching directly affects the number of runs that the catalyst can be reutilized when operating in batch-wise mode or the time of operation when working in a continuous process.Many studies about the use of heterogeneous catalysts for transesterification treated anti-leaching performance as issue of equal importance to catalytic activities. The deactivation mechanism of heterogeneous catalysts towards transesterification can be classified into the leaching of active species and the adsorption of acidic hydrocarbons onto basic sites. The deactivation tests usually take the form of repeating the reaction cycle

Table 2 Summary of Operation Conditions for Different Metal Oxide Catalysts

\begin{tabular}{|c|c|c|c|c|c|c|c|c|c|}
\hline Catalyst & Feedstock & $\begin{array}{c}\text { Catalyst } \\
\text { Content } \\
\text { wt (\%) }\end{array}$ & $\begin{array}{c}\text { Alcohol: } \\
\text { Oil Molar } \\
\text { Ratio } \\
\end{array}$ & $\underset{{ }^{\circ} \mathrm{C}}{\text { Temp. }}$ & $\begin{array}{c}\text { Pressure } \\
\mathrm{MPa}\end{array}$ & $\begin{array}{l}\text { Time } \\
\text { Min. }\end{array}$ & $\begin{array}{c}\text { Other } \\
\text { Conditions }\end{array}$ & $\begin{array}{c}\text { Yield } \\
(\%)\end{array}$ & Reference \\
\hline $\mathrm{CaO}$ & Sunflower Oil & 3 & $13: 1$ & 60 & & 100 & $\begin{array}{l}\text { Stirring } 1000 \\
\text { rpm }\end{array}$ & 94 & Granados et al. (2007) \\
\hline $\mathrm{CaO}$ & Soybean Oil & 8 & $12: 1$ & 65 & & 180 & $\begin{array}{l}\text { Water } 2.03 \\
\%\end{array}$ & 95 & Liu et al. (2008a) \\
\hline $\mathrm{CaO}$ & Jatropha Oil & 1.5 & $9: 1$ & 70 & & 150 & & 93 & Zhu et al. (2006) \\
\hline $\mathrm{CaO}$ & Sunflower Oil & 3 & $41: 1$ & 252 & 24 & 26 & & 98.9 & Demirbas (2007) \\
\hline $\mathrm{CaO} / \mathrm{Li}$ & Karanja Oil & 2 & $12: 1$ & 65 & & 480 & & 94.9 & Meher et al. (2006) \\
\hline $\mathrm{CaO} / \mathrm{KF}$ & Tallow seed Oil & 4 & $12: 1$ & 65 & & 150 & & 96.8 & Wen, et al. (2010) \\
\hline $\mathrm{MgO}$ & Soybean Oil & 3 & $36: 1$ & 260 & 28.7 & 10 & $\begin{array}{l}\text { Stirring } 1000 \\
\text { rpm }\end{array}$ & 99 & Wang and Yang (2007) \\
\hline $\mathrm{MgO} / \mathrm{Li}$ & Soybean Oil & 6 & $9: 1$ & 65 & & 120 & $\begin{array}{l}\text { Stirring } 800 \\
\text { rpm }\end{array}$ & 89.1 & Wen, et al. (2010) \\
\hline $\mathrm{SrO}$ & Soybean Oil & 3 & $12: 1$ & 65 & & 30 & & 90 & Liu et al. (2007) \\
\hline $\mathrm{ZnO}$ & Palm kernel Oil & 3 & $6: 1$ & 200 & 50 & 60 & $\begin{array}{l}\text { Stirring } 350 \\
\text { rpm }\end{array}$ & 86.1 & Jitputti et al. (2006) \\
\hline $\mathrm{ZnO} / \mathrm{Li}$ & Soybean Oil & 5 & $12: 1$ & 65 & & 180 & & 96.3 & Xie et al. (2007) \\
\hline $\mathrm{ZnO} / \mathrm{Ba}$ & Soybean Oil & 6 & $12: 1$ & 65 & & 60 & & 95.8 & Xie and Yang (2007) \\
\hline $\mathrm{ZnO} / \mathrm{KF}$ & Soybean Oil & 3 & $10: 1$ & 65 & & 540 & & 87 & Xie et al. (2006) \\
\hline $\mathrm{ZnO} / \mathrm{Sr}\left(\mathrm{NO}_{3}\right)_{2}$ & Soybean Oil & 5 & $12: 1$ & 65 & & 300 & & 93.7 & Yang and Xie (2007) \\
\hline $\mathrm{ZrO}_{2}$ & Palm kernel Oil & 3 & $6: 1$ & 200 & 50 & 60 & $\begin{array}{l}\text { Stirring } 350 \\
\text { rpm }\end{array}$ & 64.5 & Jitputti et al. (2006) \\
\hline $\mathrm{ZrO}_{2} / \mathrm{SO}_{4}^{2 ?}$ & Palm kernel Oil & 3 & $6: 1$ & 200 & 50 & 60 & $\begin{array}{l}\text { Stirring } 350 \\
\text { rpm }\end{array}$ & 90.3 & Jitputti et al. (2006) \\
\hline $\mathrm{ZrO}_{2} / \mathrm{SO}_{4}^{2 ?}$ & Cotton seed Oil & 2 & $12: 1$ & 230 & 10 & 480 & Stirring & 85 & Chen et al. (2007) \\
\hline $\mathrm{ZrO}_{2} / \mathrm{WO}_{3}$ & Waste acid Oil & & 9:1 & 150 & & 120 & & 96 & Park et al. (2010) \\
\hline $\mathrm{ZrO}_{2} / \mathrm{WO}_{3} / \mathrm{Al}_{2} \mathrm{O}_{3}$ & Soybean Oil & & $40: 1$ & 300 & & 480 & & 94 & Furuta et al. (2004) \\
\hline $\mathrm{TiO}_{2} / \mathrm{SO}_{4}^{2 ?}$ & Cotton seed Oil & 2 & $12: 1$ & 230 & 10 & 480 & Stirring & 90 & Chen et al. (2007) \\
\hline
\end{tabular}


several times and measuring the catalytic activity in the interval between each cycle. If the deactivation of the catalyst is unavoidable, a method for regenerating its initial activity was suggested in most cases (Lee et al., 2009). Larger amount of leached species was observed when glycerol is present because Ca diglyceroxide is formed due to the reaction between $\mathrm{CaO}$ and glycerol and this is a more soluble compound than $\mathrm{CaO}$ (Granados et al., 2009).

Kouzu et al. (2009a, 2009b) pointed out that some soluble substance was leached away from the $\mathrm{CaO}$ solid base catalyst during the transesterification reaction. The amount of the soluble substance corresponded to 10.5 wt $\%$ of the employed catalyst. They also suggested that the reaction was catalyzed not only by basic sites on the surface but also by the soluble substance. This was due to moisture produced by transforming calcium oxide into calcium diglyceroxide at the beginning of the reaction. Although the leaching of solid base catalyst was inevitable even in this case, the soluble substance could be completely removed from the produced oil by cation-exchange resin. With the help of the purification technique, calcium oxide can be reused. On the other hand, Kouzu et al., (2010) showed that the catalytic activity was slightly reduced by turning calcium oxide into calcium glyceroxide, but the change in the chemical composition of the solid base catalyst provided a tolerance to air-exposure. This property offers an advantage for the practical use of the catalyst, because deterioration of the catalytic sites by $\mathrm{CO}_{2}$ and $\mathrm{H}_{2} \mathrm{O}$ contained in air is the established theory on solid base. Due to the tolerance to air-exposure, decrease in the catalytic activity was not obvious when the reaction was successively repeated with reusing the collected catalyst (Kouzu et al., 2007). Mootabadi et al. (2010) investigated the ultrasonic-assisted transesterification of palm oil in the presence of alkaline earth metal oxide catalysts $(\mathrm{CaO}, \mathrm{SrO}$ and $\mathrm{BaO})$. It was found that $\mathrm{BaO}$ had the highest residual elements detected in biodiesel with nearly 14 wt. \% of the catalyst leached into the biodiesel layer after the reaction. Meanwhile, CaO had the minimum solubility with only $0.04 \%$ weight loss. This result indicated that $\mathrm{BaO}$ had the highest solubility in biodiesel and appreciable leaching occurred.

Granados et al. (2007) found that leaching of active species was observed in the reaction medium when the catalyst was activated at high temperature. However, the amount of leaching did not result in catalyst activity reduction and the catalyst was reusable for 8 cycles.
The catalytic reaction is assumed to be the result of the heterogeneous and homogeneous contributions; part of the reaction takes place on basic sites at the surface of the catalyst and the rest is due to the dissolution of the activated $\mathrm{CaO}$ in methanol that creates homogeneous leached active species. Liu et al (2008a) found that the activity $\mathrm{CaO}$ catalyst used in transesterification was stable after 20 cycles of the reaction and the biodiesel yield at $1.5 \mathrm{~h}$ was not affected much in the repeated experiments. MacLeod et al. (2008) have evaluated the stability of alkali-doped metal oxide catalysts for application to biodiesel production, concluding that metal leaching from the catalyst was detected, and this resulted in some homogeneous activity. The authors pointed out that this drawback would need to be resolved before scaling-up biodiesel production. In a recent study by Di Serio et al. (2010), the behavior of one of the more promising heterogeneous catalysts $\left(\mathrm{TiO}_{2}\right.$ supported on $\left.\mathrm{SiO}_{2}\right)$ was investigated to verify its activity and the eventual leaching effect. The study was further deepened in batch and continuous reactors by using the catalysts in pellets, to evaluate the possibility of developing an industrial process based on this catalyst. The catalyst life-time run, in a continuous tubular reactor, was determinant for this evaluation. In such a case, the catalyst performances have been determined in both a batch and a tubular continuous reactor to evaluate the suitability of this catalyst for the development of an industrial process. It was shown in the study that only a slow leaching effect was present. This effect cannot easily be evidenced in batch conditions also by repeating many times the batch runs on the same catalyst, while, continuous runs in tubular reactor are determinant for evaluating deactivation effects and industrial suitability.

It can be found that many of the studies about the use of heterogeneous catalysts for transesterification treated anti-leaching performance as issue of equal importance to catalytic activities. If the deactivation of the catalyst is unavoidable, a method for regenerating its initial activity was suggested in most cases.

\section{The Role of Emerging Technologies}

Emerging technologies are those technical innovations which represent progressive developments within a field for a competitive advantage. In the scope of biodiesel production, two main technologies have evolved in recent years which have proven to be of 
great advantage to the industry; ultrasonication and microwave irradiation.

\section{Synergy between Microwave Irradiation and Heterogeneous Catalysis}

Microwave heating compares very favorably over conventional methods, where heating can be relatively slow and inefficient because transferring energy into a sample depends upon convection currents and the thermal conductivity of the reaction mixture. Previous results showed that application of radio frequency microwave energy offers a fast, easy route to this valuable biofuel with advantages of enhancing the reaction rate and improving the separation process (Hernando et al., 2007; Refaat et al., 2008; El Sherbiny et al., 2010). In all these attempts conventional alkali homogenous catalysts were employed. Recently, Koberg et al. (2010) explored the optimization of biodiesel production probing the combination of the microwave irradiation of oil (soybean oil or cooked oil) and $\mathrm{SrO}$ as a solid metal oxide catalyst. The authors reported that this combination accelerated the reaction (to less than $60 \mathrm{~s}$ ), maintaining a very high conversion (99\%) and high efficiency. Other studies which have also supported the high efficiency of biodiesel production by the combination of microwave irradiation and heterogeneous catalyst include a recent study by Zhang et al. (2010) using heteropolyacid solid catalyst and a previous study by Carlin et al. (2009) using calcium methoxide.

\section{Synergy between Ultrasonication and Heterogeneous Catalysis}

The use of ultrasonication also provides a promising alternative to the use of conventional transesterification. Since this reaction can only occur in the interfacial region between the liquids and also due to the fact that fats and alcohols are not totally miscible, transesterification is a relatively slow process. As a result, a vigorous mixing is required to increase the area of contact between the two immiscible phases, and thus to produce an emulsion. Previous researches have indicated that the ultrasonication provides the mechanical energy for mixing and the required energy for initiating the transesterification reaction. Previous results showed that low frequency ultrasound is an efficient, time saving and economically functional, offering a lot of advantages over the conventional classical procedure. The reaction time is reduced dramatically; the static separation time is reduced remarkably, and the yield is generally higher (Hsiao et al., 2010; Refaat and El Sheltawy, 2008; Stavarache et al., 2007). In a recent study by Kumar et al. (2010), it was shown that the combination of ultrasonication and solid catalyst reduced the reaction time compared to the conventional batch processes with $98.53 \%$ biodiesel yield.

\section{CONCLUSION}

The most important concluding remarks in this study are:

Two crucial steps are important for an efficient heterogeneous transesterification process; appropriate catalyst selection and careful catalyst preparation. Calcium oxide is the metal oxide catalyst most frequently applied for biodiesel synthesis, probably due to its cheap price, minor toxicity and high availability. Calcium oxide possesses relatively high basic strength and less environmental impacts due to its low solubility in methanol and its easier handling as compared to $\mathrm{KOH} / \mathrm{NaOH}$. Calcium oxide will probably bring about as the good productivity as $\mathrm{NaOH}$ do, by taking advantage of the easy product recovery and the environmentally benign process. There have been several reports on the usage of zirconia as a solid acid catalyst for transesterification of different oils rather than other transition metal oxides due to its strong acidity and it was found that the acidity is promoted when the surface of these metal oxides contains anions like sulfate and tungstate. Some results emphasized the advantage of co-existence of two different basic-oxide components in the catalyst for transesterification. Increases in metal oxide performances can be obtained by using nanocrystalline forms rather than commercial grade catalysts. This study has stressed the importance of catalyst preparation step. Several methods for the preparation of solid catalysts for the transesterification process were described. Many studies about the use of heterogeneous catalysts for transesterification treated anti-leaching performance as issue of equal importance to catalytic activities. If the deactivation of the catalyst is unavoidable, a method for regenerating its initial activity was suggested in most cases. The use of solid metal oxides as catalysts in oil transesterification is well established. It is recommended that new researches in the field be directed to, but not limited to, introducing a novel catalyst, making a crucial modification in an existing catalyst, describing a method for increasing the activity of a catalyst, using a treated metal oxide, using a mixed metal oxide, ...etc. The synergy between emerging 
technologies as ultrasonication and microwave irradiation, on one side, and heterogeneous catalysis, on the other side, for the production of biodiesel appears to be very promising. However, this needs to be further investigated for possible scale-up for industrial application.

\section{REFERENCES}

Abreu, F. R.; Alvez, M. B.; Macêdo, C. C. S.; Zara, L. F.; Suarez, P. A. Z., (2005). New multi-phase catalytic systems based on tin compounds active for vegetable oil transesterificaton reaction. J. Mol. Catal. A-Chem., 227 (1-2), 263-267 (5 pages).

Alba-Rubio, A. C.; Santamaría-González, J.; Mérida-Robles, J. M.; Moreno-Tost, R.; Martin-Alonso, D.; Jiménez-López, A.; Maireles-Torres, P.,(2010). Heterogeneous transesterification processes by using $\mathrm{CaO}$ supported on zinc oxide as basic catalysts. Catal. Today, 149 (3-4), 281-287 (7 pages).

Albuquerque, M. C. G.; Jiménez-Urbistondo, I.; SantamaríaGonzález, J.; Mérida-Robles, J. M.; Moreno-Tost, R.; Rodríguez-Castellón, E.; Jiménez-López, A.; Azevedo, D. C. S.; Cavalcante Jr, C. L.; Maireles-Torres, P., (2008). CaO supported on mesoporous silicas as basic catalysts for transesterification reactions. Appl. Catalysis A-Gen., 334 (12), 35-43 (9 pages).

Alonso, D. M.; Mariscal, R.; Granados, M. L.; Maireles-Torres, P., (2009). Biodiesel preparation using $\mathrm{Li} / \mathrm{CaO}$ catalysts: Activation process and homogeneous contribution. Catal. Today, 143 (1-2), 167-171 (5 pages).

Alonso, D. M.; Vila, F.; Mariscal, R.; Ojeda, M.; Granados, M. L.; Santamaría-González, J., (2010). Relevance of the physicochemical properties of $\mathrm{CaO}$ catalysts for the methanolysis of triglycerides to obtain biodiesel. Catal. Today, Article in Press.

Antunes, W. M.; Veloso, C. D. and Henriques, C. A., (2008). Transesterification of soybean oil with methanol catalyzed by basic solids. Catal. Today., 133 (135), 548-554 (7 pages).

Aramendia, M. A.; Benitez, J. A.; Borau, V.; Jimenez, C.; Marinas, J. M.; Ruiz, J. R.; Urbano, F., (1999). Characterization of various magnesium oxides by XRD and H-1 MAS NMR spectroscopy. J. Solid State Chem., 144 (1), 25-29 (5 pages).

Arzamendia, G.; Arguinarena, E.; Campo, I.; Zabala, I. S.; Gandia, L. M., (2008). Alkaline and alkaline-earth metals compounds as catalysts for the methanolysis of sunflower oil. Catal. Today., 133 (135), 305-313 (9 pages).

Babu, N. S.; Sree, R.; Prasad, P. S. S.; Lingaiah, N., (2008). Roomtemperature transesterification of edible and nonedible oils using a heterogeneous strong basic $\mathrm{Mg} / \mathrm{La}$ catalyst. Energ. Fuel., 22 (3), 1965-1971 (7 pages).

Bancquart, S.; Vanhove, C.; Pouilloux, Y.; Barrault, J., (2001). lycerol transesterification with methyl stearate over solid basic catalysts. I. Relationship between activity and basicity. Appl. Catal. A-Gen., 218 (1-2), 1-11 (11 pages).

Bournay, L.; Casanave, D.; Delfort, B.; Hillion, G.; Chodorge, J. A., (2005). New heterogeneous process for biodiesel production: A way to improve the quality and the value of the crude glycerin produced by biodiesel plants. Catal. Today, 106 (1-4), 190-192 (3 pages).

Cao, F.; Chen, Y.; Zhai, F; Li, J.; Wang, J.; Wang, X.; Wang, S.; Zhu, W., (2008). Biodiesel production from high acid value waste frying oil catalyzed by superacid heteropolyacid. Biotechnol. Bioeng., 101 (1), 93-100 (8 pages).

Carlin, C. A.; Tompsett, G. A.; Weingarten, R.; Conner, W. C., (2009). Microwave assisted transesterification of soybean oil using heterogeneous catalysts. Conference Proceedings, 2009 AIChE Annual Meeting, 09AIChE.

Chen, H.; Peng, B.; Wang, D.; Wang, J., (2007). Biodiesel production by the transesterification of cottonseed oil by solid acid catalysts. Frontiers of Chemical Engineering in China, 1 (1) 11-15 (5 pages)

Chorkendorff, I.; Niemantsverdriet, J. W., (2003). Concepts of Modern Catalysis and Kinetics. Wiley-VCH, Weinheim, Germany.

D’Cruz, A.; Kulkarni, M. G.; Meher, L. C.; Dalai, A. K., (2007). Synthesis of biodiesel from canola oil using heterogeneous base catalyst. J. Am. Oil Chem. Society, 84 (10), 937-943 (7 pages).

de Almeida, R. M.; Noda, L. K.; Gonçalves, N. S.; Meneghetti, S. M. P.; Meneghetti, M. R., (2008). Transesterification reaction of vegetable oils, using superacid sulfated $\mathrm{TiO}$-base catalysts. Appl. Catal. A-Gen., 347 (1), 100-105 (5 pages).

Demirbas, A., (2007). Biodiesel from sunflower oil in supercritical methanol with calcium oxide. Energ. Convers. Manage., 48 (3), 937-941 (5 pages).

Di Serio, M.; Ledda, M.; Cozzolino, M.; Minutillo, G.; Tesser, R.; Santacesaria, E., (2006). Transesterification of soybean oil to biodiesel by using heterogeneous basic catalysts. Ind. Eng. Chem. Res., 45 (9), 3009-3014 (6 pages).

Di Serio, M.; Tesser, R.; Pengmei, L.; Santacesaria, E., (2008). Heterogeneous catalysts for biodiesel production. Energ. Fuel., 22 (1), 207-217 (11 pages).

Di Serio, M.; Tesser, R.; Casale, L.; D’Angelo, A.; Trifuoggi, M.; Santacesaria, E., (2010). Heterogeneous catalysis in biodiesel production: The influence of leaching. Top. Catal., 53 (1112), 811-819 (9 pages).

Dossin, T. F.; Reyniers, M. F.; Marin, G. B., (2006a). Kinetics of heterogeneously MgO-catalyzed transesterification. Appl. Catal. B-Environ., 62 (1-2), 35-45 (11 pages).

Dossin, T. F.; Reyniers, M. F.; Berger, R. J.; Marin, G. B., (2006b). Simulation of heterogeneously MgO-catalyzed transesterification for fine-chemical and biodiesel industrial production. Appl. Catal. B-Environ., 67, (1-2), 136-148 (13 pages).

Ebiura, T.; Echizen, T.; Ishikawa, A.; Murai, K.; Baba, T., (2005). Selective transesterification of triolein with methanol to methyl oleate and glycerol using alumina loaded with alkali metal salt as a solid-base catalyst. Appl. Catal. A-Gen., 283 (12), 111-116 (6 pages).

El Sherbiny, S. A.; Refaat, A. A. and El Sheltawy, S. T., (2010). Production of biodiesel using the microwave technique. Journal of Advanced Research, Article in Press.

Freedman, B.; Butterfield, R. O.; Pryde, E. H., (1986). "Transesterification Kinetics of Soybean Oil”. J. Am. Oil Chem. Society, 63 (10), 1375-1380 (6 pages).

Furuta, S.; Matsuhashi, H.; Arata, K., (2004). Biodiesel fuel production with solid superacid catalysis in fixed bed reactor under atmospheric pressure. Catal. Commun., 5 (12), 721-723 (3 pages).

Furuta, S.; Matsuhashi, H.; Arata, K., (2006). Biodiesel fuel production with solid amorphouszirconia catalysis in fixed bed reactor. Biomass Bioenerg., 30 (10), 870-873 (4 pages).

Georgogianni, K. G.; Katsoulidis, A. K.; Pomonis, P. J.; Manos, G.; Kontominas, M. G., (2009a). Transesterification of rapeseed oil for the production of biodiesel using homogeneous and heterogeneous catalysis. Fuel Process. Tech., 90 (7-8), 10161022 (7 pages).

Georgogianni, K. G.; Katsoulidis, A. K.; Pomonis, P. J.; Kontominas, M. G., (2009b). Transesterification of soybean frying oil to biodiesel using heterogeneous catalysts. Fuel Process. Tech., 90 (5), 671-676 (6 pages). 
Granados, M. L.; Poves, M. D. Z.; Alonso, D. M.; Mariscal, R.; Galisteo, F. C.; Moreno-Tost, R.; Santamaria, J.; Fierro, J. L. G., (2007). Biodiesel from sunflower oil by using activated calcium oxide. Appl. Catal. B-Environ., 73 (3-4), 317-326 (10 pages)

Granados, M. L.; Alonso, D. M.; Sadaba, I.; Ocon, P., (2009). Leaching and homogeneous contribution in liquid phase reaction catalysed by solids: The case of triglycerides methanolysis using CaO. Appl. Catal. B-Environ., 89 (1-2), 265-272 (8 pages).

Gryglewicz, S., (1999). Rapeseed oil methyl esters preparation using heterogeneous catalysts. Bioresource Tech., 70 (3), 249253 (5 pages).

Gryglewicz, S., (2000). Alkaline-earth metal compounds as alcoholysis catalysts for ester oils synthesis. Appl. Catal. AGen., 192 (1), 23-28 (6 pages).

Hattori, H., (2001). Solid base catalysts: generation of basic sites and application to organic synthesis. Appl. Catal. A-Gen., 222 (1-2), 247-259 (13 pages).

Hattori, H., (2004). Solid Base Catalysts: Generation, characterization, and catalytic behavior of basic sites. Journal of the Japan Petroleum Institute, 47 (2), 67-81 (15 pages).

Hernando, J.; Leton, P.; Matia, M. P.; Novella, J. L.; AlvarezBuilla, J., (2007). Biodiesel and FAME synthesis assisted by microwaves: Homogeneous batch and flow processes. Fuel, 86 (10-11), 1641-1644 (4 pages).

Hsiao, M.-C.; Lin, C.-C.; Chang, Y.-H. and Chen, L.-C., (2010). Ultrasonic mixing and closed microwave irradiation-assisted transesterification of soybean oil. Fuel, 89 (12), 3618-3622 (5 pages).

Huang, K.; Xu, Q., Zhang, S.; Ren, Z. and Yan, Y., (2009). MultiStep Controlled Kinetics of the Transesterification of Crude Soybean Oil with Methanol by $\mathrm{Mg}(\mathrm{OCH} 3) 2$. Chemical Engineering \& Technology, 32 (10), 1595-1604 (10 pages).

Jitputti, J; Kitiyanan, B.; Rangsunvigit, P.; Bunyakiat, K.; Attanatho, L. and Jenvanitpanjakul, P., (2006). Transesterification of crude palm kernel oil and crude coconut oil by different solid catalysts. Chemical Engineering Journal, 116 (1), 61-66 (6 pages).

Kawashima, A.; Matsubara, K. and Honda, K., (2008). Development of heterogeneous base catalysts for biodiesel production. Bioresource Technology, 99 (9), 3439 -3443 (5 pages).

Kawashima, A.; Matsubara, K. and Honda, K., (2009). Acceleration of catalytic activity of calcium oxide for biodiesel production. Bioresource Technology, 100 (2), 696-700 (5 pages).

Kiss, A. A.; Dimian, A. C. and Rothenberg, G., (2006). Solid acid catalysts for biodiesel production-towards sustainable energy. Advanced Synthesis \& Catalysis, 348 (1-2), 75-81 (7 pages).

Knothe, G.; van Gerpen, J. and Krahl, J., (2005). The Biodiesel Handbook. AOCS Press, Champaign, IL, USA.

Koberg, M.; Abu-Much, R. and Gedanken, A., (2010). Optimization of bio-diesel production from soybean and wastes of cooked oil: Combining dielectric microwave irradiation and a SrO catalyst. Bioresource Technology, Article in Press.

Kouzu, M.; Hidaka, J.; Komichi, Y.; Nakano, H. and Yamamoto, M., (2009b). A process to transesterify vegetable oil with methanol in the presence of quick lime bit functioning as solid base catalyst. Fuel, 88 (10), 1983-1990 (8 pages).

Kouzu, M.; Kasuno, T.; Tajik, M.; Yamanak, S. and Hidak, J., (2007). Active phase of calcium oxide used as solid base catalyst for transesterification of soybean oil with refluxing methanol. Applied Catalysis A: General, 334 (1-2), 357-365 (9 pages).
Kouzu, M.; Kasuno, T.; Tajika, M.; Sugimoto, Y.; Yamanaka, S. and Hidaka, J., (2008). Calcium oxide as a solid base catalyst for transesterification of soybean oil and its application to biodiesel production. Fuel, 87 (12), 2798-2806 (9 pages).

Kouzu, M.; Tsunomori, M.; Yamanaka, S. and Hidaka, J., (2010). Solid base catalysis of calcium oxide for a reaction to convert vegetable oil into biodiesel. Advanced Powder Technology, 21 (4), 488-494 (7 pages).

Kouzu, M.; Yamanaka, S.; Hidaka, J. and Tsunomori, M., (2009a). Heterogeneous catalysis of calcium oxide used for transesterification of soybean oil with refluxing methanol. Appl. Catal. A: General, 355 (1-2), 94-99 (6 pages).

Kumar, D.; Kumar, G.; Poonam, and Singh, C.P., (2010). Ultrasonic-assisted transesterification of Jatropha curcus oil using solid catalyst, $\mathrm{Na} / \mathrm{SiO}_{2}$. Ultrasonics Sonochemistry, 17 (5), 839-844 (6 pages).

Lam, M.K.; Lee, K.T. and Mohamed, A. R., (2010). Homogeneous, heterogeneous and enzymatic catalysis for transesterification of high free fatty acid oil (waste cooking oil) to biodiesel: A review. Biotechnology Advances, 28 (4), 500-518 (19 pages).

Leclercq, E.; Finiels, A. and Moreau, C., (2001). Transesterification of rapeseed oil in the presence of basic zeolites and related solid catalysts. Journal of the American Oil Chemists' Society, 78 (11), 1161-1165 (5 pages).

Lee, D-W.; Park, Y-M. and Lee, K-Y., (2009). Heterogeneous Base Catalysts for Transesterification in Biodiesel Synthesis. Catalysis Surveys from Asia, 13 (2), 63-77 (15 pages).

Li, X.; Lu, G.; Guo, Y.; Wang, Y.; Zhang, Z:, Liu, X. and Wang, Y., (2007). A novel solid superbase of Eu2O3/Al2O3 and its catalytic performance for the transesterification of soybean oil to biodiesel. Catal. Commun., 8 (12), 1969-1972 (4 pages).

Liu, C.; Lv, P.; Yuan, Z.; Yan, F. and Luo, W., (2010). The nanometer magnetic solid base catalyst for production of biodiesel. Renewable Energy, 35 (7), 1531-1536 (6 pages).

Liu, X.; He, H.; Wang, Y. and Zhu, S., (2007). Transesterification of soybean oil to biodiesel using $\mathrm{SrO}$ as a solid base catalyst. Catalysis Communications, 8 (7), 11071111 (5 pages)

Liu, X.; He, H.; Wang, Y.; Zhu, S. and Piao, X., (2008a). Transesterification of soybean oil to biodiesel using $\mathrm{CaO}$ as a solid base catalyst. Fuel, 87 (2), 216-221 (6 pages).

Liu, X.; Piao, X.; Wang, Y.; Zhu, S. and He, H., (2008b). Calcium methoxide as a solid base catalyst for the transesterification of soybean oil to biodiesel with methanol. Fuel, Volume 87 (7), 1076-1082 (7 pages).

López, D. E.; Goodwin Jr, J.G.; Bruce, D. A. and Lotero, E., (2005). Transesterification of triacetin with methanol on solid acid and base catalysts. Applied Catalysis A: General, 295 (2), 97-105 (9 pages).

López, D.E.; Suwannakarn, K.; Bruce, D. A. and Goodwin Jr., J. G., (2007). Esterification and transesterification on tungstated zirconia: effect of calcination temperature. Journal of Catalysis, 247 (1), 43-50 (8 pages).

López, D. E.; Goodwin, J.G.; Bruce, D. A. and Furuta, S., (2008). Esterification and transesterification using modified-zirconia catalysts. Applied Catalysis A: General, 339 (1), 76-83 (8 pages).

Lotero, E.; Liu, Y.; Lopez, D.E.; Suwannakarn, K.; Bruce, D.A. and Goodwin Jr., J.G. (2005). Synthesis of Biodiesel via Acid Catalysis. Industrial \& Engineering Chemical Research, 44 (14), 5353-5363 (11 pages).

Macêdo, C. C. S.; Abreu, F. R.; Tavares, A. P.; Alves, M. B.; Zara, L. F.; Rubim, J. C. and Suarez, P. A. Z., (2006). New 
heterogeneous metal-oxides based catalyst for vegetable oil trans-esterification. Journal of Brazilian Chemical Society, 17 (7), 1291-1296 (6 pages)

MacLeod, C. S.; Harvey, A. P.; Lee, A. F.; Wilson, K., (2008). Evaluation of the activity and stability of alkali-doped metal oxide catalysts for application to an intensified method of biodiesel production. Chemical Engineering Journal, 135 (12), 63-70 (8 page).

Meher, L. C.; Kulkarni, M.G.; Dalai, A. K. and Naik, S. N., (2006). Transesterification of karanja (Pongamia pinnata) oil by solid basic catalysts. European Journal of Lipid Science and Technology, 108 (5), 389-397 (9 pages).

Melero, J. A.; Iglesias, J. and Morales, G., (2009). Heterogeneous acid catalysts for biodiesel production: current status and future challenges. Green Chemistry, 11 (9), 1285-1308 (24 pages).

Mootabadi, H.; Salamatinia, B.; Bhatia, S. and Abdullah, A. Z., (2010). Ultrasonic-assisted biodiesel production process from palm oil using alkaline earth metal oxides as the heterogeneous catalysts. Fuel, 89 (8), 1818-1825 (8 pages).

Music, S.; Dragcevic, D. and Popovic, S., (2007). Influence of synthesis route on the formation of $\mathrm{ZnO}$ particles and their morphologies Journal of Alloys and Compounds, 429 (1-2), 242-249 (8 pages)

Ngamcharussrivichai, C.; Totarat, P. and Bunyakiat, K., (2008). $\mathrm{Ca}$ and $\mathrm{Zn}$ mixed oxide as a heterogeneous base catalyst for transesterification of palm kernel oil. Applied Catalysis A: General, 341 (1-2), 77-85 (9 pages).

Park, N-K.; Lee, Y. J.; Han, G. B.; Ryu, S. O.; Lee, T. J.; Chang, C. H.and Han, G.Y., (2008). Synthesis of various zinc oxide nanostructures with zinc acetate and activated carbon by a matrix-assisted method. Colloids and Surfaces A: Physicochemical and Engineering Aspects, 313(314), 66-71 (6 pages)

Park, Y-M.; Chung, S-H.; Eom, H. J.; Lee, J-S. and Lee, K-Y., (2010). Tungsten oxide zirconia as solid superacid catalyst for esterification of waste acid oil (dark oil). Bioresource Technology, 101 (17), 6589-6593 (5 pages).

Peng, B-X.; Shu, Q.; Wang, J-F.; Wang, G-R.; Wang, D-Z. and Han, M-H., (2008). Biodiesel production from waste oil feedstocks by solid acid catalysis. Process Safety and Environmental Protection, 86 (6), 441-447 (7 pages).

Peterson, G. R. and Scarrah, W. P., (1984). Rapeseed oil transesterification by heterogeneous catalysis. Journal of the American Oil Chemists' Society, 61 (10), 1593-1596 (4 pages).

Ramos, M. J.; Casas, A.; Rodríguez, L.; Romero, R. and Pérez, A., (2008). Transesterification of sunflower oil over zeolites using different metal loading: a case of leaching and agglomeration studies. Applied Catalysis A: General, 346 (1-2), 79-85 (7 pages).

Ramu, S.; Lingaiah, N.; Prabhavathi Devi, B. L. A.; Prasad, R. B. N.; Suryanarayana, I. and Sai Prasad, P. S., (2004). Esterification of palmitic acid with methanol over tungsten oxide supported on zirconia solid acid catalysts: effect of method of preparation of the catalyst on its structural stability and reactivity. Applied Catalysis A: General, 276 (1-2), 163168 (6 pages).

Reddy, C. R. V.; Oshel, R. and Verkade, J. G., (2006). RoomTemperature Conversion of Soybean Oil and Poultry Fat to Biodiesel Catalyzed by Nanocrystalline Calcium Oxides. Energy \& Fuels, 20 (3), 1310-1314 (5 pages).

Refaat, A. A.; El Sheltawy, S. T. and Sadek, K. U., (2008). Optimum reaction time, performance and exhaust emissions of biodiesel produced by microwave irradiation. International Journal of Environmental Science and Technology, 5 (3), 315-322 (8 pages).

Refaat, A. A. and El Sheltawy, S. FT., (2008). Comparing three options for biodiesel production from waste vegetable oil. WIT Transactions on Ecology and the Environment, Waste Management and the Environment IV, Vol. 109, WIT Press, ISSN 1743-3541, p, 133-140 (8 pages).

Refaat, A. A. (2010). Different techniques for the production of biodiesel from waste vegetable oil. Int. J. Environ. Sci. Tech, 7 (1), 183-213 (21 pages).

Russbueldt, B. M. E. and Hoelderich, W. F., (2010). New rare earth oxide catalysts for the transesterification of triglycerides with methanol resulting in biodiesel and pure glycerol. Journal of Catalysis, 271 (2), 290-304 (15 pages).

Sakai, T.; Kawashima, A. and Koshikawa, T., (2009). Economic assessment of batch biodiesel production processes using homogeneous and heterogeneous alkali catalysts. Bioresource Technology, 100 (13), 3268-3276 (9 pages).

Salinas, D.; Guerrero, S. and Araya, P., (2010). Transesterification of canola oil on potassium-supported $\mathrm{TiO} 2$ catalysts. Catalysis Communications, 11 (8), 773-777 (5 pages).

Samarghandi, M. R.; Nouri, J.; Mesdaghinia, A. R.; Mahvi, A. H.; Nasseri, S.; Vaezi, F., (2007). Efficiency removal of phenol, lead and cadmium by means of UV/ TiO2/ H2O2 processes. Int. J. Environ. Sci. Tech., 4 (1), 19-26 (8 pages).

Samart, C.; Chaiya, C. and Reubroycharoen, P., (2010). Biodiesel production by methanolysis of soybean oil using calcium supported on mesoporous silica catalyst. Energy Conversion and Management, 51 (7), 1428-1431 (4 pages).

Sato, S.; Takahashi, R.; Kobune, M. and Gotoh, H., (2009). Basic properties of rare earth oxides. Applied Catalysis A: General, 356 (1), 57-63 (7 pages).

Singh, A.; He, B.; Thompson, J. and van Gerpen, J., (2006). Process Optimization of Biodiesel Production using Different Alkaline Catalysts. Applied Engineering in Agriculture, 22 (4), 597-600 (4 pages)

Sivasamy, A.; Cheah, K.Y.; Fornasiero, P.; Kemausuor, F.; Zinoviev, S. and Miertus, S., (2009). Catalytic Applications in the Production of Biodiesel from Vegetable Oils. ChemSusChem, 2 (4), 278-300 (23 pages).

Smith, G.V. and Notheisz, F., (2006). Heterogeneous Catalysis in Organic Chemistry. Academic Press Inc., New York, NY, USA.

Sree, R.; Babu, S.; Sai Prasad, P. S. and Lingaiah, N., (2009). Transesterification of edible and non-edible oils over basic solid Mg/Zr catalysts. Fuel Processing Technology, 90 (1), 152-157 (7 pages)

Stavarache, C.; Vinatoru, M.; Maeda, Y. and Bandow, H., (2007). Ultrasonically driven continuous process for vegeF oil transesterification. Ultrasonics Sonochemistry, 14 (4), 413-417 (5 pages).

Sue, K.; Kimura, K.; Yamamoto, M. and Arai, K., (2004). Rapid hydrothermal synthesis of $\mathrm{ZnO}$ nanorods without organics. Materials Letters, 58 (26), 3350- 3352 (3 pages).

Sun, H.; Ding, Y.; Duan, J.; Zhang, Q.; Wang, Z.; Lou, H. and Zheng, X., (2010). Transesterification of sunflower oil to biodiesel on $\mathrm{ZrO}_{2}$ supported $\mathrm{La}_{2} \mathrm{O}_{3}$ catalyst. Bioresource Technology, 101 (3), 953-958 (6 pages).

Tanabe, K. and Hoelderich, W.F., (1999). Industrial application of solid acid-base catalysts. Applied Catalysis A: General, 181 (2), 399-434 (36 pages). 
Van Gerpen, J. H., (2005). Biodiesel processing and production. Fuel Processing Technology, 86 (10), 1097-1107 (11 pages). Veljkovic, V. B.; Stamenkovic, O. S.; Todorovic, Z. B.; Lazic, M. L. and Skala, D. U., (2009). Kinetics of sunflower oil methanolysis catalyzed by calcium oxide. Fuel, 88 (9), 15541562 (9 pages).

Veriansyah, B.; Kim, J-D.; Min, B. K.; Shin, Y. H.; Lee, Y-W. and Kim, J., (2010). Continuous synthesis of surfacemodified zinc oxide nanoparticles in supercritical methanol. The Journal of Supercritical Fluids, 52 (1), 76-83 (8 pages).

Verziu, M.; Cojocaru, B.; Hu, J.; Richards, R.; Ciuculescu, C.; Filip P. and Parvulescu, V. I., (2008). Sunflower and rapeseed oil transesterification to biodiesel over different nanocrystalline $\mathrm{MgO}$ catalysts. Green Chemistry, 10 (4), 373-381 (9 pages).

Vujicic, Dj.; Comic, D.; Zarubica, A.; Micic, R. and Boskovic, G., (2010). Kinetics of biodiesel synthesis from sunflower oil over $\mathrm{CaO}$ heterogeneous catalyst. Fuel, 89 (8), 20542061 (8 pages).

Wan, T.; Yu, P.; Gong, S.; Li, Q. and Luo, Y., (2008). Application of $\mathrm{KF} / \mathrm{MgO}$ as a heterogeneous catalyst in the production of biodiesel from rapeseed oil. Korean Journal of Chemical Engineering, 25 (5), 998-1003 (6 pages).

Wang, H.; Wang, M.; Liu, S.; Zhao, N.; Wei, W. and Sun, Y., (2006). Influence of preparation methods on the structure and performance of $\mathrm{CaO}-\mathrm{ZrO} 2$ catalyst for the synthesis of dimethyl carbonate via transesterification. Journal of Molecular Catalysis A: Chemical, 258 (1-2), 308-312 (5 pages).

Wang, L. and Yang, J., (2007). Transesterification of soybean oil with nano-MgO or not in supercritical and subcritical methanol. Fuel, 86 (3), 328-333 (6 pages).

Wen, L.; Wang, Y.; Lu, D.; Hu, S. and Han, H., (2010). Preparation of $\mathrm{KF} / \mathrm{CaO}$ nanocatalyst and its application in biodiesel production from Chinese tallow seed oil. Fuel, 89 (9), 2267-2271 (5 pages).

Wen, Z.; Yu, X.; Tu, S-T.; Yan, J. and Dahlquist, E., (2010). Synthesis of biodiesel from vegetable oil with methanol catalyzed by Li-doped magnesium oxide catalysts. Applied Energy, 87 (3), 743-748 (6 pages).

Xie, W. and Huang, X., (2006). Synthesis of Biodiesel from Soybean Oil using Heterogeneous $\mathrm{KF} / \mathrm{ZnO}$ Catalyst. Catalysis Letters, 107 (1-2), 53-59 (7 pages).
Xie, W. and Yang, Z., (2007). Ba-ZnO catalysts for soybean oil transesterification. Catalysis Letters, 117 (3-4), 159-165.

Xie, W.; Peng, H. and Chen, L., (2006). Calcined Mg-A hydrotalcites as solid base catalysts for methanolysis of soybean oil. Journal of Molecular Catalysis A: Chemical, 246 (1-2), 24-3 2 (9 pages).

Xie, W. L.; Yang, Z. Q. and Chun, H., (2007). Catalytic Properties of Lithium-Doped ZnO Catalysts Used for Biodiesel Preparations. Industrial \& Engineering Chemical Research, 46 (24), $7942-7949$ (8 pages).

Yan, S.; Kim, M.; Mohan, S.; Salley, S. O. and Simon Ng, K.Y., (2010). Effects of preparative parameters on the structure and performance of $\mathrm{Ca}-\mathrm{La}$ metal oxide catalysts for oil transesterification. Applied Catalysis A: General, 373, (12), 104-111 (8 pages).

Yan, S.; Kim, M.; Salley, S. O. and Simon Ng, K. Y., (2009b). Oil transesterification over calcium oxides modified with lanthanum. Applied Catalysis A: General, 360 (2), 163-170 (8 pages).

Yan, S. L.; Salley, S. O. and Simon Ng, K. Y., (2009a). Simultaneous transesterification and esterification of unrefined or waste oils over $\mathrm{ZnO}-\mathrm{La}_{2} \mathrm{O}_{3}$ catalysts. Applied Catalysis A: General, 353 (2), 203-212 (10 pages).

Yang, Z. and Xie, W., (2007). Soybean oil transesterification over zinc oxide modified with alkali earth metals. Fuel Processing Technology, 88 (6), 631-638 (8 pages).

Yoosuk, B.; Udomsap, P.; Puttasawat, B. and Krasae, P., (2010). Improving transesterification acitvity of $\mathrm{CaO}$ with hydration technique. Bioresource Technology, 101 (10), 3784-3786 (3 pages).

Zabeti, M.; Wan Daud, WM. A. and Aroua, K., (2009). Activity of solid catalysts for biodiesel production: A review. Fuel Processing Technology, 90 (6), 770-777 (8 pages).

Zhang, S.; Zu, Y.-G.; Fu, Y.-J.; Luo, M.; Zhang, D.-Y. and Efferth, T., (2010). Rapid microwave-assisted transesterification of yellow horn oil to biodiesel using a heteropolyacid solid catalyst. Bioresource Technology, 101 (3), 931-936 (6 pages)

Zhu, H.; Wu, Z.; Chen, Y.; Zhang, P.; Duan, S.; Liu, X. and Mao, Z., (2006). Preparation of Biodiesel Catalyzed by Solid Super Base of Calcium Oxide and Its Refining Process. Chinese J. Catal., 27 (5), 391-396 (6 pages).

\section{AUTHOR (S) BIOSKETCHES}

Refaat, A. A., BSc. (Hons), MSc., is an assistant lecturer in the Department of Chemical Engineering, Faculty of Engineering, Cairo University, Egypt. Email: aarefaat@hotmail.com

How to cite this article: (Harvard style)

Refaat, A. A., (2011). Biodiesel production using solid metal oxide catalysts. Int. J. Environ. Sci. Tech., 8 (1), $203-221$. 